\title{
Population sequencing of two endocannabinoid metabolic genes identifies rare and common regulatory variants associated with extreme obesity and metabolite level
}

Olivier Harismendy ${ }^{1,2+}$, Vikas Bansal ${ }^{3 \dagger}$, Gaurav Bhatia ${ }^{4}$, Masakazu Nakano ${ }^{1,2}$, Michael Scott ${ }^{5}$, Xiaoyun Wang ${ }^{1,2}$, Colette Dib ${ }^{6}$, Edouard Turlotte ${ }^{6}$, Jack C Sipe ${ }^{5}$, Sarah S Murray ${ }^{3}$, Jean Francois Deleuze ${ }^{6}$, Vineet Bafna ${ }^{4,7}$, Eric J Topol ${ }^{3,5}$, Kelly A Frazer ${ }^{1,2,7^{*}}$

\begin{abstract}
Background: Targeted re-sequencing of candidate genes in individuals at the extremes of a quantitative phenotype distribution is a method of choice to gain information on the contribution of rare variants to disease susceptibility. The endocannabinoid system mediates signaling in the brain and peripheral tissues involved in the regulation of energy balance, is highly active in obese patients, and represents a strong candidate pathway to examine for genetic association with body mass index (BMI).

Results: We sequenced two intervals (covering $188 \mathrm{~kb}$ ) encoding the endocannabinoid metabolic enzymes fattyacid amide hydrolase (FAAH) and monoglyceride lipase (MGLL) in 147 normal controls and 142 extremely obese cases. After applying quality filters, we called 1,393 high quality single nucleotide variants, 55\% of which are rare, and 143 indels. Using single marker tests and collapsed marker tests, we identified four intervals associated with BMI: the FAAH promoter, the MGLL promoter, MGLL intron 2, and MGLL intron 3. Two of these intervals are composed of rare variants and the majority of the associated variants are located in promoter sequences or in predicted transcriptional enhancers, suggesting a regulatory role. The set of rare variants in the FAAH promoter associated with BMI is also associated with increased level of FAAH substrate anandamide, further implicating a functional role in obesity.
\end{abstract}

Conclusions: Our study, which is one of the first reports of a sequence-based association study using nextgeneration sequencing of candidate genes, provides insights into study design and analysis approaches and demonstrates the importance of examining regulatory elements rather than exclusively focusing on exon sequences.

\section{Background}

During the past decade, the search for the underlying genetic basis of complex traits and diseases in humans has been focused on common DNA variants with a minor allele frequency $(\mathrm{MAF})>0.05$. This approach is based on the common variant common disease hypothesis [1], our increased knowledge of common variants

\footnotetext{
*Correspondence: kafrazer@ucsd.edu

+ Contributed equally

'Moores UCSD Cancer Center, University of California San Diego, 9500

Gilman Drive, La Jolla, CA 92093, USA

Full list of author information is available at the end of the article
}

[2], and improved genotyping methods [3]. The effort of the human genetics community has led, through genome-wide association studies (GWASs), to the identification of over 400 genetic loci associated with complex traits. However, GWASs have uncovered only a small fraction of the estimated heritability underlying complex phenotypes. The missing heritability is potentially accounted for by rare variants or variants in epistasis, both of which are difficult to identify via current genome-wide genotyping and analysis strategies. It has been suggested that sequencing candidate genes relevant to 
diseases in subjects at the tails of the distribution of a quantitative trait will be an efficient means to examine the contribution of rare variants to the phenotype [4].

Obesity is highly heritable [5] and recent GWASs have identified variants in approximately 15 genes that are associated with body mass index (BMI), among which are FTO [6], MC4R [7] and CTNNBL1 [8]. However, taken together these genes explain only a small fraction of the disease heritability [5]. There is little overlap between the genes identified by GWASs and previous genes identified through linkage or candidate gene studies, suggesting that the approaches have different sensitivities, likely due to the fact that GWASs examine only common variants and require stringent multiple-testing corrections. The genes associated with obesity risk to date are involved in several processes, such as adipogenesis, energy balance, appetite and satiety regulation. Genes in the endocannabinoid (EC) system are known to also be involved in regulating physiological functions associated with obesity $[9,10]$; the EC receptor 1 gene, CNR1, has been genetically associated with the trait [11]. ECs have modulatory effects on energy homeostasis by binding to cannabinoid receptors in the central nervous system or peripheral tissues, regulating appetite, food intake or eating behaviors [12,13]. Deregulation of the EC system has been shown in overweight and eating disorders, and increased levels of ECs in many tissues is linked to obesity $[14,15]$.

The fatty-acid amide hydrolase $(F A A H)$ and the monoglyceride lipase (MGLL) genes encode enzymes of the EC system; these catabolize anandamide (AEA) and 2-arachidonyl glycerol (2-AG), respectively. Thus, FAAH and MGLL enzymatic activity or expression plays a primary role in regulating metabolite levels of the EC system. Circulating levels of AEA and 2-AG are higher in obese patients and $F A A H$ expression level in adipose tissue is reduced [16,17]. A variant in FAAH (P129T) identified in obese patients results in reduced FAAH activity $[18,19]$. Despite this biological evidence, GWASs have not found significant association between obesity and EC system genes. Thus, FAAH and MGLL are excellent candidates to be sequenced in the extreme of the BMI distribution to find the extent of their genetic diversity and potential association of variants with obesity.

Currently, sequence-based association studies need to target specific intervals in the human genome to allow a sufficient number of samples to be examined. Several studies have examined exons to identify rare coding variants implicated in reduced sterol absorption and lower plasma levels of high-density lipoprotein [20], underlying cancer initiation and progression [21] and Mendelian diseases [22]. For complex diseases, regulatory variants affecting the expression of genes likely play an important role, thus justifying the sequencing of larger intervals, as was done for the 8q24 interval associated with colorectal cancer [23]. To the best of our knowledge, the approach of deep population sequencing of large candidate gene intervals has not yet been used for association studies. This is partly due to the fact that next-generation sequencing sample preparation and instruments are not yet optimized to sequence intervals in a large number of individuals. Additionally, the methods for using population sequence data to ascertain variant calling, including indels, are still being developed. Lastly, there is a lack of computational and experimental methods to analyze rare variants $(<1 \%$ allele frequency) associated with diseases.

In this report, we explore the genetic diversity of $188 \mathrm{~kb}$ of sequence encompassing the $F A A H$ and $M G L L$ genes in 289 individuals and use variants from the whole allelic frequency spectrum to investigate association with extreme obesity (BMI $\geq 40 \mathrm{~kg} / \mathrm{m}^{2}$ ). We identify all the variants present in the two gene intervals, establish a number of quality filters to generate a set of high quality variants and perform association testing with obesity using two different approaches: a chi-square analysis appropriate for common variants (MAF > 0.01) and a collapsing method [24] for rare variants (MAF < 0.01). We identify 20 common variants in $M G L L$ associated with high BMI and discover three intervals containing sets of rare variants (referred to as rare locus-variants) in both MGLL and FAAH. Most of the associated variants lie in regulatory elements, either close to the gene promoter or in transcriptional enhancers, as determined by chromatin signatures in HeLa and other cell types. In addition, we show the association of a rare locus-variant in the $F A A H$ promoter with increased plasma levels of AEA, thus providing an independent validation of the genetic association with obesity.

\section{Results and discussion}

\section{Selection of samples at extremes of the BMI distribution}

To increase the power of our study to detect variants associated with extreme obesity in the FAAH and MGLL genes, we sequenced DNA from individuals at the extremes of the BMI distribution in the CRESCENDO cohort, which consists of 2,958 Caucasian individuals aged 55 years or older and was established to study obesity treatment (average BMI is $35 \mathrm{~kg} / \mathrm{m}^{2}$; Figure 1 ). This strategy is based on the premise that a significant excess of sequence variants in one extreme compared to the other extreme that is not due to stratification is an indication of genetic association with the phenotype. We selected 289 individuals of European ancestry from both tails of the BMI distribution for both genders of the CRESCENDO cohort; 73 men and 70 women with a $\mathrm{BMI}>40 \mathrm{~kg} / \mathrm{m}^{2}$ (referred to as cases) and 74 men and 72 women with a BMI $<30 \mathrm{~kg} / \mathrm{m}^{2}$ (referred to as 


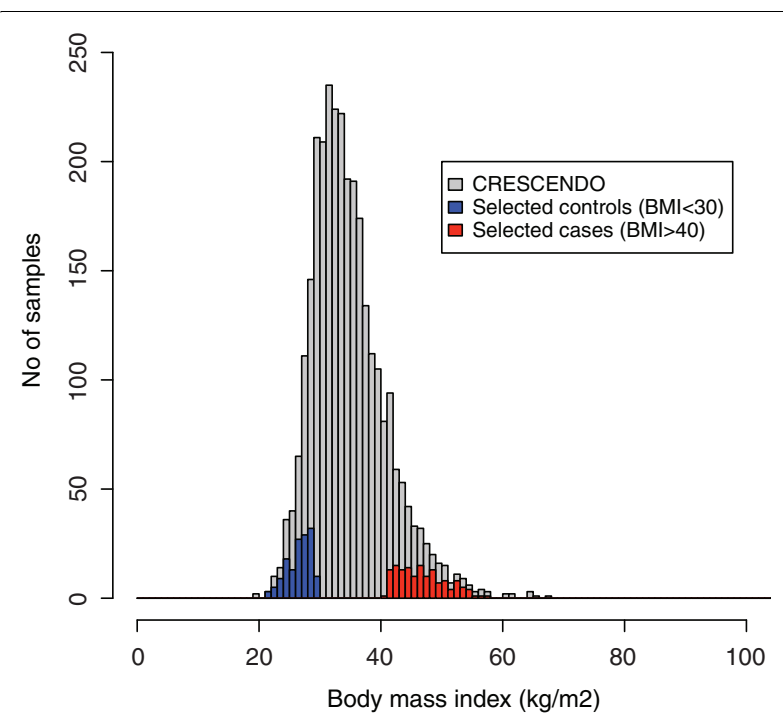

Figure $1 \mathrm{BMI}$ distribution in the CRESCENDO cohort (grey) and in the selected controls (147 samples with $B M I \leq 30 \mathrm{~kg} / \mathrm{m}^{2}$, blue) and cases (142 samples with $B M I \geq 40 \mathrm{~kg} / \mathrm{m}^{2}$, red).

controls). The cohort consists mostly of overweight people and thus only $24 \%$ of our control population has a $\mathrm{BMI}<25 \mathrm{~kg} / \mathrm{m}^{2}$. For this reason, our population is particularly well suited to identify the genetic variants associated with extreme obesity $\left(\right.$ BMI $\left.>40 \mathrm{~kg} / \mathrm{m}^{2}\right)$.

\section{Targeted sequencing of $188 \mathrm{~kb}$ of sequence spanning FAAH and MGLL}

We amplified the 32-kb interval encompassing $F A A H$ and the $156-\mathrm{kb}$ interval encompassing $M G L L$ by long range PCR (LR-PCR) using 40 overlapping amplicons (Figure 2A, B). Of the targeted base pairs, $77 \%$ were covered by two distinct amplicons and the remaining $23 \%$ (43.6 kb) located at the edges of the two intervals were covered by only one amplicon. After equimolar pooling of the amplicons, each sample was sequenced at a median coverage greater than $60 \times$ across the targeted intervals (Table S1 in Additional file 1). The median of the average coverage for the samples was $187 \times$. In all samples, $85 \%$ of the targeted bases were covered at $20 \times$ or more (Figure 2C). To perform sequence-based association studies, the consistency and reproducibility of coverage across targeted bases from sample to sample is of high importance. Coverage is directly correlated with accuracy in base calling and the same bases need to be analyzed across numerous samples. In general, targeted sequencing using LR-PCR provides good reproducibility, ensuring that any particular base will be covered equally well in different samples, provided there is a sufficient average coverage depth [25]. However, regions of high GC content are difficult to amplify and sequence [25] and in our current study are insufficiently covered in a number of samples (Figure 2A, B). Restricting the analysis to bases called in greater than $90 \%$ of the samples, we have $99.9 \%$ sensitivity to call homozygous bases (assuming a $3 \times$ coverage requirement) and $99.7 \%$ sensitivity to call heterozygous bases (assuming a $6 \times$ coverage requirement).

\section{Identification, filtering, and characterization of single nucleotide variants}

We identified 1,448 single nucleotide variants (SNVs) that are polymorphic in the 289 sequenced samples using the MAQ SNP calling algorithm [26]. We implemented a number of quality filters to establish a reliable set of SNVs. We initially examined only the 1,433 SNVs that were biallelic, of which 1,403 (97.9\%) were in Hardy-Weinberg equilibrium (HWE) at a $P$-value < 0.001 in the controls. The majority (19 of 27) of SNVs failing HWE had a lower than expected heterozygosity. Heterozygous genotypes in sequence data can be undercalled for coverage or quality reasons. We observed a few cases where a 'hidden' variant (SNV or indel) was located in the vicinity of the SNV that failed the HWE test, leading to an erroneous call for alignment reasons. We imposed additional quality criteria where we assigned an 'N' genotype for a SNV covered by less than three reads or with poor consensus genotype quality (MAQ phred score < 10). Finally, we removed 16 SNVs for which less than $90 \%$ of the samples had valid genotype calls. These successive filters leave us with 1,393 SNVs confidently called in the sequenced cohort (Additional file 2). In addition to these 1,393 biallelic variants we also observed 5 tri-allelic variants (Table S2 in Additional file 1 ), of which 4 are private variants and observed only once $(\mathrm{MAF}=0.002)$ and one is observed three times. This small number of tri-allelic variants ( $0.34 \%$ of the $1,448 \mathrm{SNVs})$ is consistent with the proportion of tri-allelic SNPs in the Seattle SNP database, which contains 67 tri-allelic SNPs (0.224\%) [27]. For the biallelic SNVs identified, 433 of 1,393 (31\%) are present in the dbSNP databases (v.129). Of the 960 (69\%) novel SNVs, 512 (37\%) were singletons (the minor allele was found only once) and 762 (55\%) had a MAF $<1 \%$. Since we sequenced 578 chromosomes, rare variants with a frequency of approximately 1\% will be present in 6 chromosomes, and can thus be reliably identified. Our results demonstrate the power of deep population resequencing to discover rare variants (Additional file 3).

Coding variants are likely to have large effect sizes and their functional consequences can be predicted. We found 14 coding variants, of which 5 are common $(\mathrm{MAF}>0.05)$ and 9 are rare $(\mathrm{MAF}<0.003$; observed only once or twice) (Table 1). Most of the common variants were previously known whereas the rare variants are novel. Of the 14 coding variants, 4 and 5 are 
(a) LR-PCR amplicons

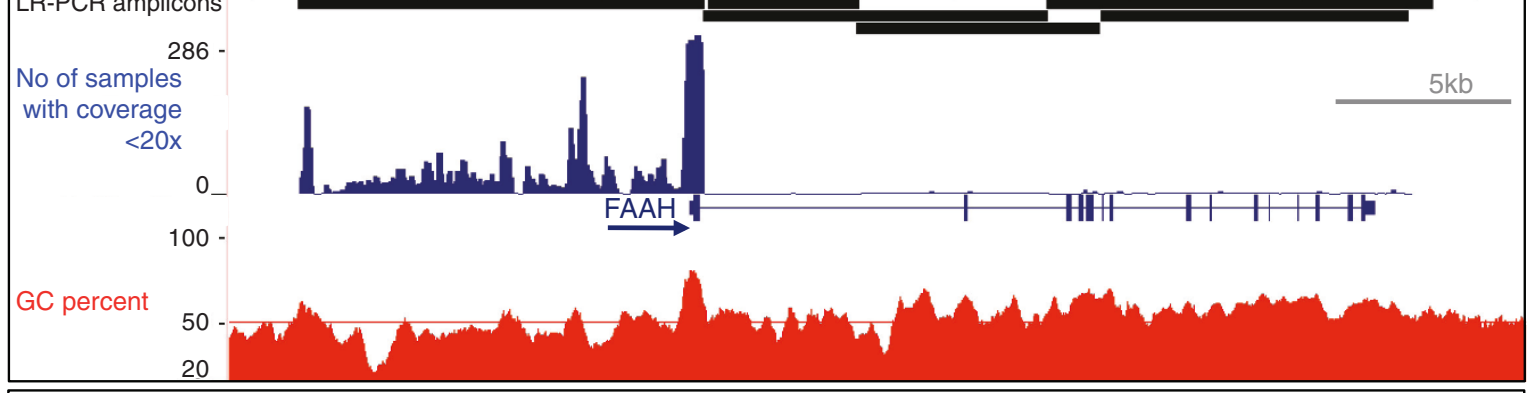

(b)

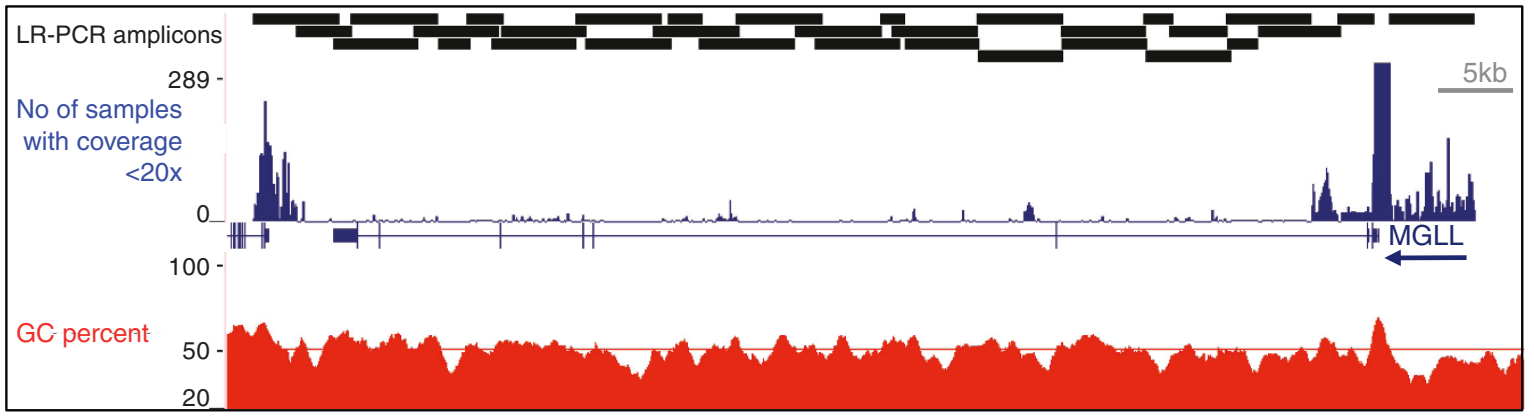

(c)

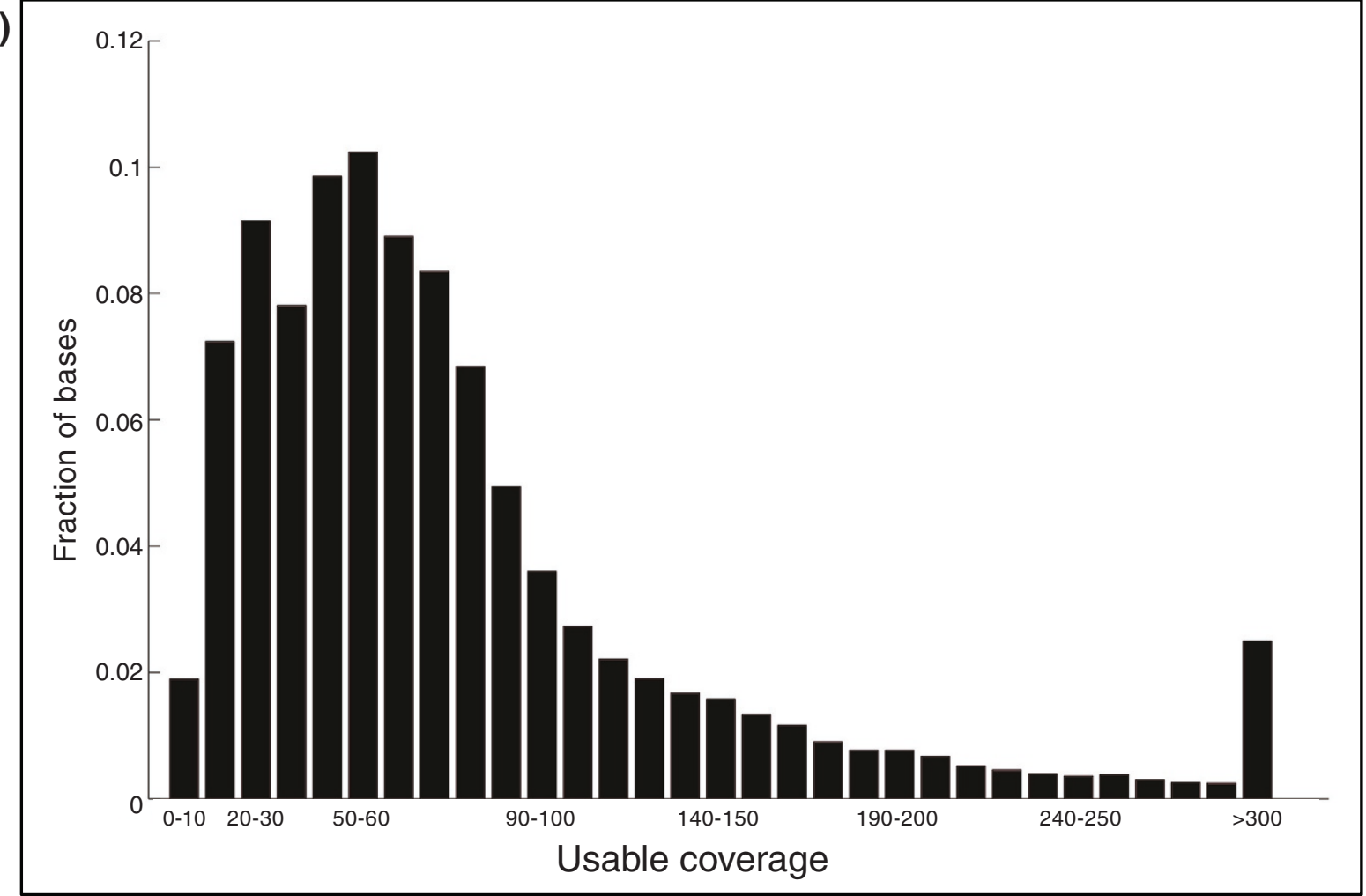

Figure 2 Sequence coverage distribution. (a,b) Genome Browser tracks showing locations of the 40 LR-PCR amplicons (black rectangles), the number of samples with coverage below 20x (blue histogram, 100-bp windows) and GC percent (red histogram, 10-bp windows) along the FAAH (a) and MGLL (b) re-sequenced intervals. The ends of the intervals have lower coverage due to the fact they were amplified by a single amplicon. The $5^{\prime}$ end of the FAAH gene was successfully amplified but coverage is low due to difficulty sequencing high GC content regions. The high GC content at the $5^{\prime}$ end of the MGLL gene resulted in an inability to successfully design PCR primer pairs despite several attempts. (c) Distribution of the fraction of bases ( $y$-axis) sequenced at increasing usable coverage ( $x$-axis) for sequence-based association studies. Usable coverage is defined at each base as the minimum coverage reached by $90 \%$ or more of the samples. 
Table 1 Coding sequence variants in the two genes and SIFT analysis

\begin{tabular}{|c|c|c|c|c|c|c|c|c|c|c|}
\hline Coordinate & Alleles & Gene & $\begin{array}{l}\text { Codon } \\
\text { change }^{a}\end{array}$ & $\begin{array}{l}\text { Amino acid } \\
\text { change }\end{array}$ & dbSNP & Coding type & $\begin{array}{l}\text { SIFT } \\
\text { prediction }\end{array}$ & $\begin{array}{l}\text { SIFT } \\
\text { score }\end{array}$ & MAF & $\begin{array}{l}\text { Number } \\
\text { observed }\end{array}$ \\
\hline Chr1_46643348 & $\mathrm{C} / \mathrm{A}$ & $F A A H$ & CCA-aCA & P129T & rs324420 & $\begin{array}{l}\text { Non- } \\
\text { synonymous }\end{array}$ & Tolerated & 0.46 & 0.216 & 123 \\
\hline Chr1_46643944 & $\mathrm{G} / \mathrm{A}$ & FAAH & GGG-aGG & G226R & Novel & $\begin{array}{l}\text { Non- } \\
\text { synonymous }\end{array}$ & Tolerated & 0.15 & 0.002 & 1 \\
\hline Chr1_46643960 & $\mathrm{C} / \mathrm{T}$ & FAAH & CCC-CtC & P231L & Novel & $\begin{array}{l}\text { Non- } \\
\text { synonymous }\end{array}$ & Tolerated & 0.63 & 0.002 & 1 \\
\hline Chr1_46643996 & $\mathrm{G} / \mathrm{A}$ & FAAH & CGC-CaC & $\mathrm{R} 243 \mathrm{H}$ & Novel & $\begin{array}{l}\text { Non- } \\
\text { synonymous }\end{array}$ & Damaging & 0 & 0.003 & 2 \\
\hline Chr1_46644333 & $G / A$ & FAAH & GAG-GAa & E274E & Novel & Synonymous & Tolerated & 0.96 & 0.052 & 30 \\
\hline Chr1_46644573 & $\mathrm{T} / \mathrm{C}$ & $F A A H$ & TGT-TGC & C299C & rs324419 & Synonymous & Tolerated & 1 & 0.176 & 101 \\
\hline Chr1_46646834 & $\mathrm{G} / \mathrm{A}$ & FAAH & GCG-GCa & A356A & rs45476901 & Synonymous & Tolerated & 1 & 0.002 & 1 \\
\hline Chr3_128893754 & $\mathrm{C} / \mathrm{T}$ & MGLL & GCA-aCA & A307T & Novel & $\begin{array}{l}\text { Non- } \\
\text { synonymous }\end{array}$ & Tolerated & 0.55 & 0.003 & 2 \\
\hline Chr3_128893854 & $\mathrm{A} / \mathrm{C}$ & MGLL & ATT-ATg & $1273 \mathrm{M}$ & Novel & $\begin{array}{l}\text { Non- } \\
\text { synonymous }\end{array}$ & Tolerated & 0.13 & 0.002 & 1 \\
\hline Chr3_128896571 & $\mathrm{T} / \mathrm{C}$ & MGLL & $\mathrm{CTA}-\mathrm{CTg}$ & L251L & rs4881 & Synonymous & Tolerated & 1 & 0.073 & 42 \\
\hline Chr3_128922669 & $\mathrm{C} / \mathrm{T}$ & MGLL & GCA-aCA & A143T & Novel & $\begin{array}{l}\text { Non- } \\
\text { synonymous }\end{array}$ & Tolerated & 0.36 & 0.002 & 1 \\
\hline Chr3_128983328 & $C / T$ & MGLL & GAC-aAC & $\mathrm{D} 86 \mathrm{~N}$ & Novel & $\begin{array}{l}\text { Non- } \\
\text { synonymous }\end{array}$ & Damaging & 0 & 0.002 & 1 \\
\hline Chr3_129023325 & $\mathrm{C} / \mathrm{T}$ & MGLL & CGG-CGa & R19R & rs11538698 & Synonymous & Tolerated & 0.86 & 0.052 & 30 \\
\hline Chr3_129023335 & $\mathrm{G} / \mathrm{A}$ & MGLL & TCC-TtC & $\mathrm{S} 16 \mathrm{~F}$ & Novel & $\begin{array}{l}\text { Non- } \\
\text { synonymous }\end{array}$ & Damaging & 0.01 & 0.002 & 1 \\
\hline
\end{tabular}

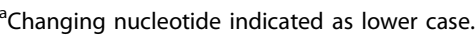

non-synonymous coding variants in $F A A H$ and $M G L L$, respectively, and 3 of them, all rare, are predicted to be damaging by SIFT [28]. Interestingly, rs324420, a coding allele, is predicted as tolerated despite evidence of its negative effect on FAAH enzymatic activity [19], thus showing the limitation of the predictive algorithm and underscoring the value of experimental validation by functional assays.

\section{Quality assessment of the sequence-based genotypes}

The use of next-generation sequencing for association studies is still an emerging field, and thus base-calling errors need to be better characterized to avoid confounding the association testing analysis. In particular, one needs to distinguish systematic errors due to the technology and random sampling errors due to low coverage. Here we use two separate assessment strategies to estimate the accuracy of our sequencing and define error types.

\section{Comparison to an alternative genotyping method}

To evaluate the accuracy of the filtered genotype calls using the sequence data, we independently genotyped 19 SNVs, present in dbSNP, in the two sequenced genes using the MassARRAY genotyping platform. We compared the sequence-derived genotypes for each sample to the corresponding MassARRAY genotypes and found that $1.8 \%$ (97 of 5,487 comparisons) of the genotypes were in disagreement between the two methods (Table 2). Sixtyfour out of 97 (66\%) of the discordant genotypes were located at three loci. Further inspection of these loci show that they are systematic errors due to the presence of a hidden un-annotated variant in the vicinity. The HWE statistic was higher for the MassARRAY genotypes at two loci, indicating that the MassARRAY genotyping was more often incorrect, likely due to the fact that the hidden variants were not considered during the primer design. Thirty out of 97 (31\%) of the discordant genotypes were located in 10 of the remaining 13 loci. They were missed heterozygous in the sequence-based genotypes $(\mathrm{N} / \mathrm{N})$ and were likely a result of low sequence coverage and are thus random sampling errors. The last three discrepancies were due to missing genotypes. These results indicate that sequencing-based genotyping is more robust than MassARRAY genotyping to the presence of a hidden variant. A similar genotyping error type has been observed genome-wide with microarray genotyping, where 85 of 130 discrepant calls were due to 'hidden' SNPs [29]. This comparison shows us that $1.2 \%$ of all genotypes are discordant due to systematic errors in the genotyping platform whereas $0.6 \%$ are discordant due to low coverage or random sampling errors in the sequence data.

\section{Comparison between replicate samples}

The above comparison to an established genotyping method only assesses accuracy at well-behaved bases 
Table 2 Concordance of the sequence-derived genotype calls with genotypes from the MassARRAY genotyping for 19 SNPs

\begin{tabular}{|c|c|c|c|c|c|c|c|}
\hline \multirow[b]{2}{*}{ SNP rsID } & \multirow[b]{2}{*}{$\begin{array}{c}\text { Number matching } \\
\text { genotype }\end{array}$} & \multirow[b]{2}{*}{$\begin{array}{l}\text { Number of under- } \\
\text { calls }^{\mathrm{a}}\end{array}$} & \multirow[b]{2}{*}{$\begin{array}{c}\text { Number of over- } \\
\text { calls }^{\mathbf{b}}\end{array}$} & \multicolumn{4}{|c|}{ Hardy-Weinberg statistic } \\
\hline & & & & $\begin{array}{c}\text { Number of } \mathrm{N} / \\
\mathrm{N}^{\mathrm{c}}\end{array}$ & Sequencing & MassARRAY & $\begin{array}{l}\text { Hidden } \\
\text { variant }\end{array}$ \\
\hline rs594323 & 253 & 1 & 33 & 2 & 1.2 & 4.2 & SNP at $22 \mathrm{bp}$ \\
\hline rs9759081 & 272 & 15 & 2 & 0 & 0 & 8.6 & SNP at $19 \mathrm{bp}$ \\
\hline rs9852837 & 276 & 0 & 13 & 0 & 0.2 & 0.01 & Indel at $38 \mathrm{bp}$ \\
\hline rs4141964 & 287 & 1 & 0 & 1 & 1.6 & 1.2 & - \\
\hline rs324419 & 287 & 2 & 0 & 0 & 0.7 & 0.9 & - \\
\hline rs17203666 & 289 & 0 & 0 & 0 & 0.6 & 0.6 & - \\
\hline rs11715363 & 286 & 3 & 0 & 0 & 0.1 & 0 & - \\
\hline rs17203659 & 288 & 1 & 0 & 0 & 0.2 & 0 & - \\
\hline rs6778770 & 287 & 0 & 1 & 0 & 0.2 & 0.3 & - \\
\hline rs17282181 & 283 & 4 & 2 & 0 & 0 & 0.2 & - \\
\hline rs497897 & 287 & 1 & 1 & 0 & 1.2 & 0.2 & - \\
\hline rs567384 & 283 & 4 & 2 & 0 & 2.3 & 0.6 & - \\
\hline rs3773155 & 286 & 3 & 0 & 0 & 0 & 0 & - \\
\hline rs3773159 & 286 & 1 & 2 & 0 & 2.3 & 2.1 & - \\
\hline rs13076593 & 288 & 1 & 0 & 0 & 0.8 & 0.1 & - \\
\hline rs936839 & 288 & 1 & 0 & 0 & 1.1 & 1.2 & - \\
\hline rs13066225 & 289 & 0 & 0 & 0 & 0.1 & 0.1 & - \\
\hline rs324420 & 289 & 0 & 0 & 0 & 0 & 0 & - \\
\hline rs7652615 & 289 & 0 & 0 & 0 & 0.4 & 0.4 & - \\
\hline
\end{tabular}

${ }^{a}$ Genotype called as reference homozygote by sequencing and heterozygote by MassARRAY or heterozygote by sequencing and alternative homozygote by MassARRAY. ${ }^{b}$ Genotype called as heterozygote by sequencing and reference homozygote by MassARRAY or alternative homozygote by sequencing and heterozygote by MassARRAY. 'Uncalled genotype or tri-allelic in one of the two.

present in dbSNP. In order to assess all other bases as well as potential false positive variants, we compared sequence-based genotypes between independent duplicates of nine samples (independent library preparation and sequencing runs). We identified $448 \mathrm{SNVs}$ present in one or more samples of 9 replicated samples; 429 of these passed the quality control filters established in the sequenced population, resulting in 1,697 pairs of genotypes to compare (most SNVs being present in more than one pair of duplicates). Of these, 1,612 (95\%) pairs matched between the two replicates (Figure 3). Of note, the 5-kb regions upstream of $M G L L$ and FAAH covered by single amplicons (Figure 2A, B) had 13 discrepant pairs; this increased error rate is likely due to the lower sequence coverage. Fifteen discrepant pairs had low coverage $(<20 \times)$ in one sample, which can create random sampling errors. Five discrepant pairs were homozygous alternative in one sample and heterozygous in the other.

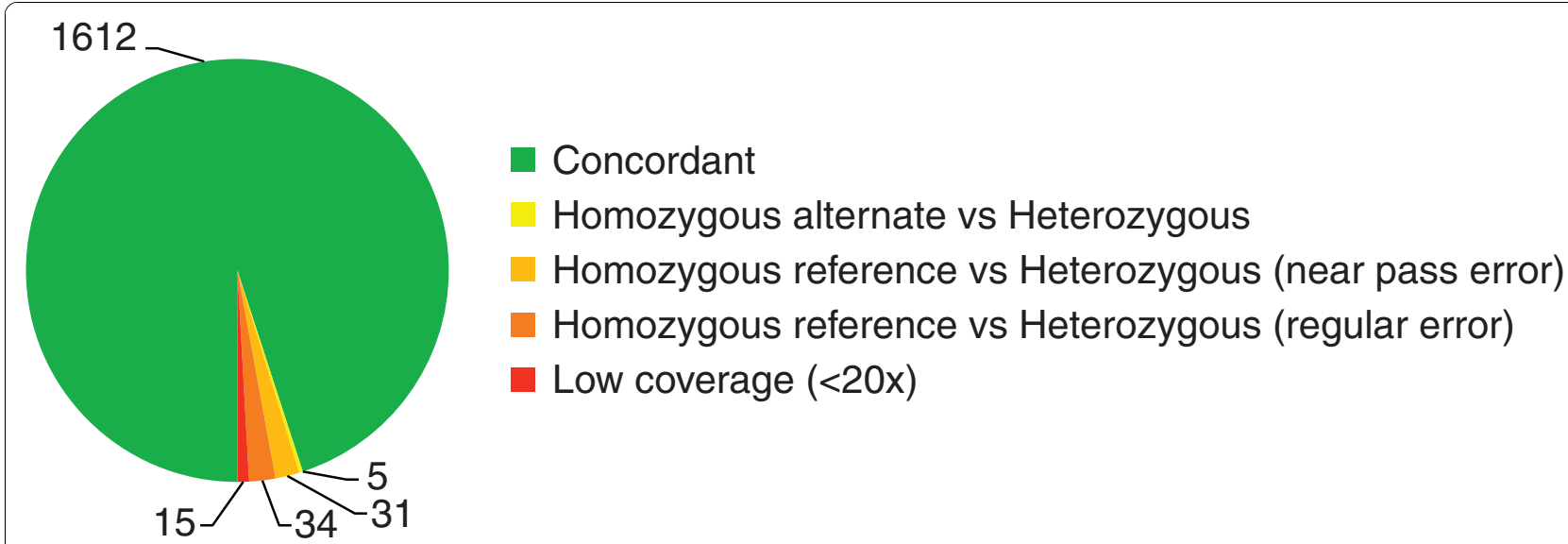

Figure 3 Quality control of SNV identification. Distribution of the matching status of 1,697 genotypes obtained from the 9 replicated samples. 
The remaining 65 pairs were heterozygous in one sample and homozygous reference in the other, of which 31 had some evidence of the alternative allele in the raw consensus call but failed Bayesian SNV caller (referred to as a near-pass error; see Materials and methods); 34 pairs did not show such evidence for the presence of an alternative allele. It is important to distinguish near-pass errors from regular errors since they can be rescued with optimized SNV calling or leveraging population information [30]. Our analysis reveals that in 289 samples, only $2.8 \%((15+34) / 1,697)$ of all variants were likely miscalled due to random sampling, whereas $2.1 \%$ $((31+5) / 1,697)$ show an alternative allele under-calling, which was not sufficient to create Hardy-Weinberg disequilibrium. These data demonstrate that targeted sequencing using LR-PCR as the sample preparation method produces high sample-to-sample variant calling reproducibility.

\section{Detection of indels}

The identification of insertions and deletions from short reads (36 bp) remains a challenge for two reasons: it is computationally prohibitive to align millions of short reads to a reference sequence allowing for gaps; and the alignments with indels are not reliable for short reads. The availability of paired-end reads alleviates the first problem since one end of the read can be anchored on the reference sequence and the second end can then be gap-aligned using a full Smith-Waterman alignment. According to previous reports, the SNV:indel ratio varies from $10: 1$ to $7: 1$ [29,31]; thus, we expect to find approximately 140 indels in the re-sequenced region. We used the MAQ indelpe module to perform pairedend mapping of the reads and to identify potential indel positions in each sample. This method identifies a large number of false positives and requires additional filtering to reliably call indels in the population. We identified 240 potential indel positions, 54 of which match an entry and allele call in dbSNP (v.129). Of the 240 indels, 106 are single base pair indels, 53 of them are located in homopolymer runs of $5 \mathrm{bp}$ or longer and 24 in runs of $10 \mathrm{bp}$ or longer, 21 indels are 2 bases long and, of these, 14 are located di-nucleotide repeats of length 2 or more; 143 indels pass HWE testing in the control samples, of which 49 match an allele in dbSNP. Interestingly, 5 indels failing HWE testing are bona fide variants present in $\mathrm{dbSNP}$. The percentage of indels passing the HWE test $(59.6 \%)$ is considerably lower than that of SNVs (97.9\%), reflecting the difficulty to accurately call indels using short-read technology.

By sequencing 142 high BMI cases and 147 low BMI controls, we overall identified 1,393 high-confidence SNVs and 143 indels passing HWE testing for use in sequence-based association studies.

\section{Association of variants with BMI}

As the sequenced samples were selected from the two tails of the BMI distribution, we performed association tests for each SNV with BMI as a binary trait to determine if any of the identified sequence variants in the FAAH and MGLL genes are associated with high BMI. We performed sequence-based association analysis using two different approaches: a chi-square analysis on all variants and a collapsing method for lower frequency variants.

\section{Single marker tests}

We compared the allele frequencies of the variants in the cases and controls and assessed statistical significance using allelic chi-square test for each variant. Nineteen SNVs and one indel show an association with BMI (Table 3; chi-square $P$-value $\leq 0.01$ ), of which 16 remain associated $(P<0.01)$ and 4 marginally associated $(P$ value approximately 0.01 ) after performing 5,000 permutation tests (Table 3 ). These associated variants are located in the non-coding part of the MGLL gene: three variants upstream, seven in intron 2 and ten in intron 3 (Figure 4A). The 20 associated variants are split between two linkage disequilibrium (LD) blocks demarcated by a recombination hotspot (Figure $4 \mathrm{~A}$ ) and could potentially affect regulatory elements located upstream or intronic to the gene. The variants in the left block have a lower frequency (MAF < 0.05) than the ones in the right block (MAF > 0.15). Interestingly, the risk effects of the minor alleles in the left and right blocks are opposite; most of the minor alleles in the right block are protective while most of those in the left block are associated with risk (Table 3). Of note, four of the associated variants were present on at least one of the genotyping arrays used in the original obesity GWASs (Table 3) but were not found associated with the trait. It is important to note that our study design, which is looking at extreme obesity (BMI $\geq 40 \mathrm{~kg} / \mathrm{m}^{2}$ ) in an overweight population (mean BMI $=35 \mathrm{~kg} / \mathrm{m}^{2}$ ), is different from most published GWASs, which missed the association at the MGLL loci.

Several other SNPs located in FTO [6,32-35], MC4R [7,36,37], CNR1 [11,38,39], CTNNBL1 [8], INSIG2 [40] or PFKP [35] have been associated with high BMI or obesity by GWASs. In order to relate these previous results to the population in our study, we genotyped the associated SNPs in the 289 individuals we sequenced. Looking at BMI as a binary trait, we found that all the SNPs located in FTO were associated with high BMI (Pvalue < 0.05; Table S3 in Additional file 1). None of SNPs located in the other genes showed association with high BMI. These results demonstrate that despite differences in the sample selection criteria, our cohort is appropriate to replicate the association of variants in the FTO gene interval, one of the strongest associations in 
Table 3 List of variants associated with high BMI by single marker tests

\begin{tabular}{|c|c|c|c|c|c|c|c|c|c|c|}
\hline \multirow[b]{2}{*}{ LD block } & \multirow[b]{2}{*}{ SNV-ID } & \multirow[b]{2}{*}{ Chr 3 coordinate } & \multirow[b]{2}{*}{ Gene location } & \multirow[b]{2}{*}{ Minor/major alleles } & \multicolumn{3}{|c|}{ MAF } & \multicolumn{2}{|c|}{ Chi-square } & \multirow{2}{*}{$\begin{array}{c}\text { Permutation } \\
P \text {-value }\end{array}$} \\
\hline & & & & & Cohort & Cases & Controls & $P$-value & OR & \\
\hline \multirow[t]{10}{*}{ Left } & rs16830415 & 128956957 & Intron3 & $\mathrm{C} / \mathrm{T}$ & 0.028 & 0.045 & 0.010 & 9.95E-03 & 4.59 & $8.00 \mathrm{E}-03$ \\
\hline & Chr3_128957192 & 128957192 & Intron3 & $\mathrm{G} / \mathrm{T}$ & 0.028 & 0.045 & 0.010 & 9.95E-03 & 4.59 & 8.00E-03 \\
\hline & Chr3_128958587 & 128958587 & Intron3 & $\mathrm{C} / \mathrm{T}$ & 0.043 & 0.066 & 0.021 & $6.70 \mathrm{E}-03$ & 3.39 & 5.00E-03 \\
\hline & Chr3_128958866 & 128958866 & Intron3 & $-/ T$ & 0.08 & 0.049 & 0.1103 & 7.07E-03 & 0.41 & 7.40E-03 \\
\hline & rs9832418 & 128961356 & Intron3 & $\mathrm{C} / \mathrm{T}$ & 0.028 & 0.045 & 0.010 & 9.95E-03 & 4.59 & 8.00E-03 \\
\hline & $\operatorname{rs} 547801^{a}$ & 128964929 & Intron3 & $\mathrm{T} / \mathrm{C}$ & 0.029 & 0.049 & 0.010 & 5.93E-03 & 4.96 & $5.00 \mathrm{E}-03$ \\
\hline & rs520154 & 128965687 & Intron3 & $A / G$ & 0.028 & 0.049 & 0.007 & 2.04E-03 & 7.46 & $1.20 \mathrm{E}-03$ \\
\hline & rs60963555 & 128967982 & Intron3 & $\mathrm{T} / \mathrm{C}$ & 0.026 & 0.045 & 0.007 & $3.52 \mathrm{E}-03$ & 6.91 & $1.60 \mathrm{E}-03$ \\
\hline & rs684358 & 128969940 & Intron3 & $\mathrm{G} / \mathrm{T}$ & 0.028 & 0.049 & 0.007 & 2.04E-03 & 7.46 & $1.20 \mathrm{E}-03$ \\
\hline & rs9852837 & 128973744 & Intron3 & $A / G$ & 0.028 & 0.045 & 0.010 & 9.95E-03 & 4.59 & $1.16 \mathrm{E}-02$ \\
\hline \multirow[t]{10}{*}{ Right } & rs9289319 & 129009856 & Intron2 & $\mathrm{G} / \mathrm{A}$ & 0.192 & 0.138 & 0.243 & $1.42 \mathrm{E}-03$ & 0.50 & $1.80 \mathrm{E}-03$ \\
\hline & rs9289320 & 129010946 & Intron2 & $\mathrm{G} / \mathrm{C}$ & 0.192 & 0.143 & 0.240 & 3.27E-03 & 0.53 & $6.00 \mathrm{E}-03$ \\
\hline & rs9289321 & 129011459 & Intron2 & $\mathrm{A} / \mathrm{G}$ & 0.165 & 0.123 & 0.206 & 7.84E-03 & 0.54 & $9.80 \mathrm{E}-03$ \\
\hline & rs9877819 & 129012220 & Intron2 & $A / G$ & 0.164 & 0.122 & 0.206 & 7.03E-03 & 0.54 & $7.40 \mathrm{E}-03$ \\
\hline & rs28753886 & 129013477 & Intron2 & $A / G$ & 0.163 & 0.119 & 0.206 & 4.79E-03 & 0.52 & $5.60 \mathrm{E}-03$ \\
\hline & rs35948688 & 129014938 & Intron2 & $\mathrm{C} / \mathrm{T}$ & 0.159 & 0.112 & 0.206 & 2.10E-03 & 0.49 & $2.40 \mathrm{E}-03$ \\
\hline & rs $874546^{c}$ & 129021102 & Intron2 & $\mathrm{G} / \mathrm{A}$ & 0.183 & 0.140 & 0.226 & 8.99E-03 & 0.56 & $1.00 \mathrm{E}-02$ \\
\hline & rs2011138 & 129026619 & Upstream & $\mathrm{A} / \mathrm{C}$ & 0.352 & 0.412 & 0.295 & $3.18 \mathrm{E}-03$ & 1.68 & 4.40E-03 \\
\hline & Chr3_129026621 & 129026621 & Upstream & $\mathrm{A} / \mathrm{G}$ & 0.049 & 0.021 & 0.075 & $2.65 \mathrm{E}-03$ & 0.27 & 4.00E-03 \\
\hline & Chr3_129029015 & 129029015 & Upstream & $\mathrm{A} / \mathrm{G}$ & 0.336 & 0.398 & 0.276 & $1.98 \mathrm{E}-03$ & 1.74 & $3.60 \mathrm{E}-03$ \\
\hline
\end{tabular}

apresent on the Affymetrix $500 \mathrm{k}$ genotyping array. ${ }^{\mathrm{b}}$ Also part of a locus-variant associated with high BMI using the collapsed marker test RareCover (Table 55 in Additional file 1). 'Present on the Illumina HumanHap300 genotyping array. LD, linkage disequilibrium.

recent obesity GWASs. In a recent and remarkable meta-analysis of the majority of published obesity GWASs, the authors show that the replication of the INSIG2 locus association was compromised by study design [41]. Thus, the failure to replicate originally weaker associations in our study and the failure to identify MGLL in previous GWASs can be due to insufficient power, population differences, variable study designs or selection criterion.

\section{Collapsed marker tests with RareCover}

Statistical association with single variants of low allele frequency is challenging to assess as very few samples contribute to the association test. Previous studies have used collapsing methods to study the influence of rare variants on high-density lipoprotein plasma levels [42], colorectal cancer risk [43] or type 1 diabetes [44]. More recent collapsing methods use a weighted or multivariate model. Here, we implement a model-free method (RareCover [24]; see Materials and methods) to identify an optimal set of variants of low allele frequency (MAF $\leq 0.1$ ) within a moving 5 -kb window, which maximizes the association with high BMI. We refer to variants in the 5-kb window as locus-variants. This strategy increases the power of detecting an association using variants of low allele frequency with moderate relative risk and cohort sizes.
Using RareCover on the low frequency SNVs (MAF < 0.1 , indels excluded), we identified 31 locus-variants in the FAAH and MGLL interval that are significantly associated (permutation $P$-value $<0.01$; Table $S 4$ in Additional file 1) with extreme obesity (Figure 4B, C). Most of these locus-variants are overlapping and share several SNVs; however, three distinct intervals show significant association with high BMI. The first interval is located in the $F A A H$ promoter region. The most significant locus-variant of this interval harbors 15 variants selected by RareCover for maximizing the association (permutation $P$-value $=2.2 \times 10^{-3}$; Table S4 in Additional file 1 ). Twenty-three cases and no controls carry a minor allele at the union of the 15 variants (Table S5 in Additional file 1). The second interval is located in the MGLL promoter region. RareCover identified 10 variants (permutation $P$-value $=1.4 \times 10^{-3}$ ) in the most significant locus-variant of this interval; 38 cases and 9 controls carry a minor allele at the union of the 10 variants (Tables S4 and S5 in Additional file 1). Thus, for both genes, the most significantly associated locus-variants are located upstream of the transcription start sites with potential consequences on the regulation of gene expression. Because these upstream regions have lower coverage due to their amplification by a single amplicon (Figure 2A, B), we verified that all SNV alleles found 


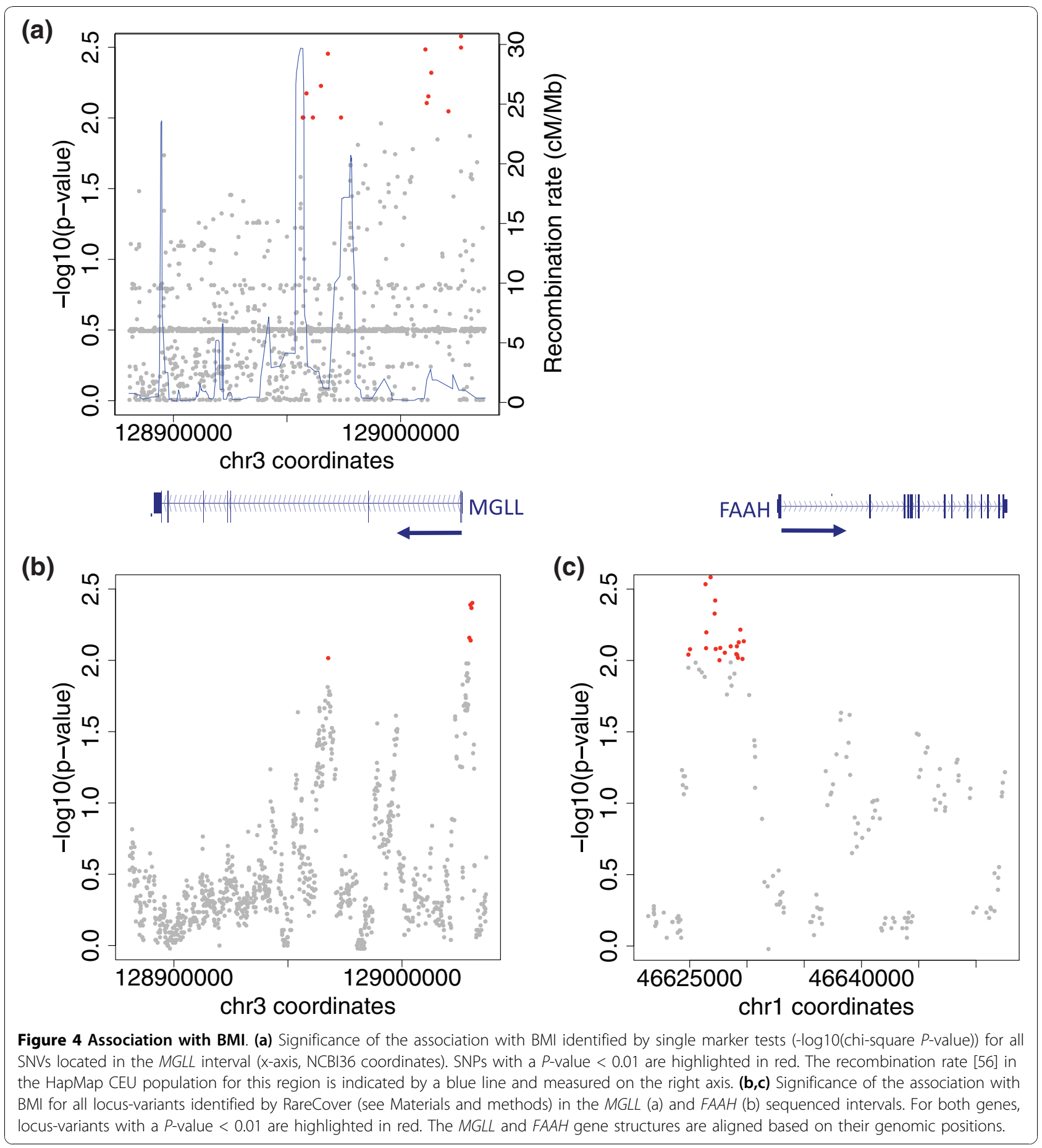

associated with BMI, either by the single marker or the RareCover collapsing method, has sufficient coverage (Table S8 in Additional file 1) to generate reliable genotypes. Finally, the third interval is located in MGLL intron 3 and overlaps with the left block SNVs associated with high BMI by single marker analysis (Figure $4 \mathrm{~A}, \mathrm{~B})$. It has only one significant locus-variant ( $P$-value $=0.0096)$ consisting of 9 variants; 25 cases and 2 controls carry a minor allele of the union of the 9 variants (Table S5 in Additional file 1). One of the nine variants in the MGLL intron 3 locus-variant (rs684358) was also identified as associated with high BMI in the single marker analysis. Interestingly, the eight other variants associated with BMI using single marker analysis are not included in the reported significant locusvariants. This is due to the fact that these variants are in 
LD and thus the associated alleles are carried by the same individual: their addition in the RareCover locusvariant would not change the $P$-value and thus they were not included. Although these eight variants are included in some other locus-variants, the $P$-value does not reach significance since its calculation differs from the single marker test by the inclusion of other variants and the finite number of permutations. The second most associated variant by the single marker test (rs520154) is included in a mildly significant locus-variant ( $P$-value approximately 0.03$)$; the seven other variants had a higher single-marker $P$-value. Of note, the right block identified by the single marker analysis harbors only more common variants (MAF > 0.15), which were not included in the RareCover analysis. Thus, in the same interval of $M G L L$ intron 3, both the single marker and RareCover tests independently identified variants with different MAFs (approximately 0.03 versus approximately 0.002 ) that are associated with high BMI.

\section{Functional annotation of the associated variants}

DNA variants located outside of coding regions can lie in transcriptional regulatory elements and have an effect on gene expression. In order to determine the potential regulatory function of the variants or locus-variants associated with high BMI, we inspected publicly available chromatin marks around the MGLL and FAAH genes. In particular, the combined location on the DNA sequence of several histone modifications as well as transcriptional co-activators and RNA polymerase has been used in HeLa cells to determine genome-wide signatures for transcriptional enhancers and promoters [45]. Interestingly, the $M G L L$ interval has 11 predicted enhancers in HeLa cells; however, there are no predicted enhancers in the $F A A H$ interval (Figure 5, track B). The locus-variant identified by RareCover in $M G L L$ intron 3 and also identified via single marker test (Figure 5, track A) overlaps an enhancer prediction. Chromatin marks corresponding to this particular enhancer are also identified in several cell types studied by the ENCODE consortium [46] (Figure 5, track C). In addition, a number of transcription factors bind this particular element in HeLa cells as shown by the ENCODE consortium [46] (Figure 5, track D) adding further evidence that it is likely to be an enhancer. Since enhancers can be active in multiple cell types, it is very likely that the variants associated with high BMI in MGLL intron 3 affect the activity of a transcriptional enhancer by modifying a transcription factor binding site, thus changing $M G L L$ gene expression in the central nervous system or other, peripheral tissues. Similarly, one of the single associated SNVs in MGLL intron 2 also lies in an enhancer prediction. This particular SNV could well be associated with high BMI because of its causal regulatory role in MGLL expression while the other SNVs in the right block could be associated because of their LD with it. Interestingly, none of the associated variants are present in evolutionarily conserved sequences, which frequently are a signature for regulatory elements. These analyses suggest that two of the intervals (MGLL intron 2 and intron 3) associated with high BMI contain regulatory variants in enhancer elements.

\section{Consequences of associated variants on EC levels}

Reduced levels of FAAH and MGLL catabolic enzymes can lead to an accumulation of their substrates AEA and 2-AG, respectively. In an attempt to link the presence of the associated alleles in high BMI patients to the level of circulating EC, we measured the plasma concentrations of AEA and 2-AG in a subset of the samples. We selected 96 obese patients with $\mathrm{BMI}>45$ $\mathrm{kg} / \mathrm{m}^{2}$ and 48 normal patients with BMI $<26 \mathrm{~kg} / \mathrm{m}^{2}$ and measured the concentration of AEA and 2-AG in the plasma using reverse phase liquid chromatography coupled to triple-quadrupole mass spectrometry (TQMS). We calibrated our measurements by comparison to deuterated standards.

None of the single variants located in MGLL and associated with high BMI showed a significant association with either AEA or 2-AG levels. Examining the most significantly associated locus-variants from each of the three intervals identified by RareCover, we compared AEA and 2-AG average levels between carriers in the obese samples versus non-carrier control samples (Table 4). Case individuals carrying the locus-variant minor alleles in $F A A H$ had significantly higher levels of AEA $(+24 \%)$ than control non-carrier individuals ( $t$-test $P$ value $=0.05)$, with a consistent trend across all classes (carrier/cases, non-carrier/cases, non-carriers/controls) (Figure S2 in Additional file 4). This trend is consistent with the higher observed levels of AEA in obesity [16], which could result from reduced expression of $F A A H$ in some obese individuals because of rare variants in the promoter region (Table 4).

\section{Conclusions}

In this study, we generated high quality sequencing data to analyze the association of DNA variants in two candidate genes, FAAH and MGLL, with extreme obesity. Deep population sequencing allows one to test for the association of alleles spanning the entire frequency spectrum. By using two different approaches, single marker tests and collapsed marker tests, we were able to identify one interval in the $F A A H$ promoter and three intervals in the MGLL gene, one each in the promoter, intron 2, and intron 3, all associated with high BMI. Most of the associated variants are rare $(\mathrm{MAF}<0.01)$ or have low frequencies $($ MAF $\approx 0.03)$ and are only accessible via 


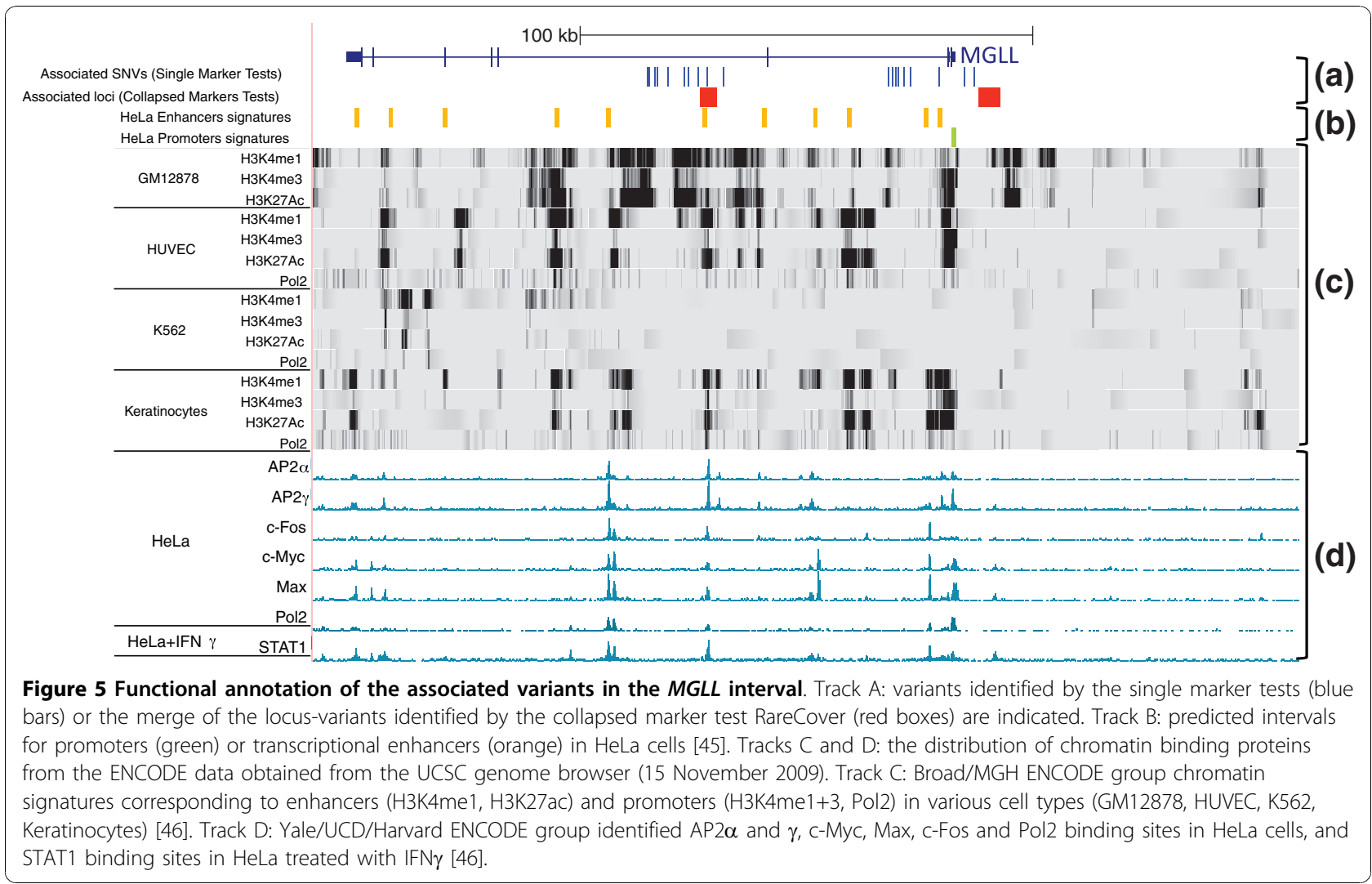

population sequencing. The single-base-pair resolution obtained in the sequencing-based association study allowed us to precisely map the associated variants to a predicted transcriptional enhancer in HeLa cells or to the promoter regions. Thus, the associated variants are likely regulating the expression of $M G L L$ and $F A A H$. By potentially affecting the overall transcription rate of the two genes, the variants can influence the EC degradation rate. A correlation between decreased expression of $F A A H$ in adipose tissues and increased circulating AEA levels has previously been observed in obese patients [16]. The expression of FAAH and MGLL in numerous tissues will make it challenging to determine the exact role that the regulatory variants identified in our study play in obesity.

Our study design examines extreme cases of obesity in an overweight population. We demonstrate the ability to replicate in our population the association of FTO variants with obesity, which is the main BMI-associated locus, thus further proving the robustness of the association and the appropriate selection of our samples to study obesity. However, some other loci, more weakly or inconsistently associated in the original GWASs, were not replicated in our samples, which is not too surprising given the sample size of our cohort is inadequate to replicate modest associations. Reciprocally, the published
GWASs did not find any association in $F A A H$ or $M G L L$ despite the presence of probes for 4 out of 20 single marker-associated variants in the genotyping microarrays used. This lack of consistency has been studied through a meta-analysis of obesity GWASs [41] in which replication was compromised by the type of population sampled, the BMI thresholds used for cases and controls, the fraction of obese people, or the time of study reflecting change in the environment. This study highlights the crucial importance of population and study design in obesity association studies for both discovery and replication. It is important to note that, in our study, we strengthen the initial genetic association by correlating it to its functional consequences in both FAAH and MGLL. Using metabolite measurements in the plasma of the sequenced samples, we verified that the set of rare variants in the $F A A H$ promoter associated with high BMI is also associated with an increased level of AEA. Additionally, we demonstrate independent associations of common and rare variants in $M G L L$ intron 3 and show that these variants overlap a predicted transcriptional enhancer, which suggests their regulatory role.

The large number of loci identified by GWASs only explains a small fraction of the estimated heritability underlying complex diseases. Since GWASs using arrays examine only common variants for association, it is 
Table 4 Average endocannabinoid levels of FAAH and MGLL rare variant carrier groups at the most significant locusvariants in the three intervals

\begin{tabular}{|c|c|c|c|c|c|c|c|c|}
\hline & \multicolumn{4}{|c|}{ AEA } & \multicolumn{4}{|c|}{ 2-AG } \\
\hline & $\mathrm{N}$ & Average $(\mathrm{pmol} / \mathrm{ml})$ & SD & $P$-value ${ }^{a}$ & $\mathbf{N}$ & Average $(\mathrm{pmol} / \mathrm{ml})$ & SD & $P$-value ${ }^{a}$ \\
\hline FAAH promoter locus-variant & & & & 0.05 & & & & 0.10 \\
\hline \multicolumn{9}{|l|}{ Carrier } \\
\hline Cases & 14 & 17.11 & 5.79 & & 14 & 10.55 & 10.67 & \\
\hline Controls & 0 & NA & NA & & 0 & NA & NA & \\
\hline \multicolumn{9}{|l|}{ Non-carrier } \\
\hline Cases & 80 & 15.13 & 5.34 & & 67 & 5.63 & 3.04 & \\
\hline Controls & 48 & 13.76 & 5.51 & & 35 & 6.98 & 4.15 & \\
\hline MGLL intron 3 locus-variant & & & & 0.49 & & & & 0.80 \\
\hline \multicolumn{9}{|l|}{ Carrier } \\
\hline Cases & 5 & 15.6 & 6.35 & & 4 & 6.43 & 2.08 & \\
\hline Controls & 0 & NA & NA & & 0 & NA & NA & \\
\hline \multicolumn{9}{|l|}{ Non-carrier } \\
\hline Cases & 89 & 15.24 & 5.44 & & 77 & 6.49 & 5.57 & \\
\hline Controls & 48 & 13.76 & 5.52 & & 35 & 6.99 & 4.16 & \\
\hline MGLL promoter locus-variant & & & & 0.36 & & & & 0.37 \\
\hline \multicolumn{9}{|l|}{ Carrier } \\
\hline Cases & 26 & 15.09 & 5.6 & & 24 & 6.31 & 3.06 & \\
\hline Controls & 3 & 13.16 & 5.38 & & 3 & 4.41 & 4.46 & \\
\hline \multicolumn{9}{|l|}{ Non-carrier } \\
\hline Cases & 68 & 15.56 & 5.43 & & 57 & 6.56 & 6.2 & \\
\hline Controls & 45 & 13.8 & 5.58 & & 32 & 7.22 & 4.11 & \\
\hline
\end{tabular}

${ }^{\mathrm{a}}$ Two-tailed $t$-test $P$-value between carriers/cases and non-carriers/controls. NA, not available.

possible that rare variants comprise an important component of the hidden heritability. Compared with previous GWASs, sequencing-based studies can examine rare variants for association with complex traits. It is believed that a significant fraction of the heritability missed by GWASs lies in rare variants. Similar to our approach, other studies have collapsed rare variants from several samples to assess a significance difference in frequency between two groups $[42,44]$. Although the effect size of rare variants cannot be accurately estimated in a relatively small cohort, it has been shown that they contribute to an incremental fraction of heritability in hypertrigyceridemia [47]. Our study is the first to use this approach on contiguous genomic intervals and not only in coding regions. This allows the identification of potential regulatory variants. Most common variants found in GWASs of common diseases lie in non-coding regions, often very distant from genes. These variants, or variants in LD with them, are thought to affect regulatory elements, as some studies have demonstrated $[48,49]$. The effect of the rare variants in common diseases might be similar and more frequently affecting regulatory elements: this hypothesis fits particularly late-onset or chronic disease etiology in which the symptoms can be the result of long-term mild imbalance in the regulation of molecular functions. As sequencing technology and bioinformatics tools improve, we will be able to reliably call copy-number variation in large cohorts and consider gene interactions to explore even further the missing heritability.

In order to improve the sensitivity of genetic association studies, the biology underlying the complex phenotype also needs to be considered. For this purpose, the epigenetic landscape, such as chromatin marks, is particularly important to identify the functional variant from a group of associated variants all in LD and go beyond the pure genetic assessment of disease susceptibility. Knowledge of the biochemical activity of the gene products is also helpful. For example, the extensive annotation of metabolic pathways constitutes a powerful paradigm with a direct measurable output. We sequenced two genes coding for metabolic enzymes important for the regulation of the EC system, and looked upstream of their consequences on BMI, at the level of their substrates, to confirm their influence. Thus, an integrated approach using deep sequencing to find rare variants, epigenetic annotation of the DNA sequence and functionally relevant endo-phenotypes 
increases the odds of finding elements of missing heritability and helps to more fully comprehend the underpinnings of complex disease etiology. With increasing availability of large scale functional datasets, integrated approaches such as ours will likely become more common in future genetic association studies.

\section{Materials and methods}

\section{Selection of samples for sequencing}

The Institutional Review Board of Sanofi Aventis approved the collection of samples from the CRESCENDO cohort [50] and the unrestricted release of the results of this study. The enrollment of participants and blood collection were carried out in accordance with the Helsinki Declaration. In particular, patients gave informed consent to the study. An initial list of 3,101 individuals in the CRESCENDO cohort were evaluated and filtered to select low and high BMI/obesity samples, representing the two extremes of this phenotype, for both genders. Individuals of European ancestry are highly represented (96\%) in the CRESCENDO cohort. To reduce false-positive findings due to differing genetic backgrounds, male and female selection was restricted to individuals of European ancestry, ranging in age from 55 to 77 years. Samples with inconsistent or aberrant measurements were removed from the set, including 52 samples from patients with inconsistent waist measurements (standard deviation > 3), 2 samples with missing biographical data, and from one subject with a nonsensical BMI $(B M I=195)$. For the low BMI/obesity sample subset, male and female subjects with a BMI of $\leq 30 \mathrm{~kg} /$ $\mathrm{m}^{2}$ were selected. For the high BMI/obesity sample subset, male and female subjects with a BMI of $\geq 40 \mathrm{~kg} / \mathrm{m}^{2}$, but $<60 \mathrm{~kg} / \mathrm{m}^{2}$, were selected to remove aberrant outliers. The last criterion used for selection was the waist measurement. First, the BMI measurements were plotted against the average waist measurements, and two outliers on the BMI/waist measurement graph were removed. Based on availability and quality of DNA, a subset of each category was selected for deep population sequencing: 73 men and 70 women with a $\mathrm{BMI}>40$ $\mathrm{kg} / \mathrm{m}^{2}$ and 74 men and 72 women with a BMI $<30 \mathrm{~kg} /$ $\mathrm{m}^{2}$ (Figure 1). DNA was isolated from whole blood collected from each of the 289 selected individuals.

Differences in ancestry between cases and controls can lead to spurious associations in case-control association studies. Although all individuals in the CRESCENDO cohort that were selected for sequencing have selfreported European ancestry, we utilized a set of ancestry informative markers to ensure that the sequenced samples have primarily European ancestry; 31 ancestry informative markers chosen from the Human Diversity Panel [51] were genotyped in the 289 samples using the Sequenom MassARRAY genotyping platform. We performed principal components analysis of the genotype data [52] using Matlab (MathWorks, Natick, MA, USA) and only the first principal component was significant, indicating lack of population structure.

\section{Long-range PCR}

Forty LR-PCR experiments were performed to amplify 31,716 bp encompassing the FAAH gene (NCBI36 chr1:46621328-46653043) and 156,556 bp encompassing the MGLL gene (NCBI36 chr3:128880456-129037011). We performed the 40 LR-PCR experiments using $5 \mathrm{ng}$ of genomic DNA, $0.5 \mu \mathrm{M}$ forward LR-PCR primers, 0.5 $\mu \mathrm{M}$ reverse LR-PCR primers (Table S6 in Additional file 1 ) in a total reaction volume of $12 \mu \mathrm{l}$, as described [2]. Following LR-PCR, the 40 amplicons $(3,129$ bp to $12,203 \mathrm{bp})$ generated using a single DNA sample template were quantified using Quant-IT technology (Invitrogen, Carlsbad, CA, USA) and combined in equimolar amounts using a liquid handling robot (Biomek NX; Beckman Coulter, Brea CA, USA).

\section{Illumina GAI library preparation}

The following steps were performed in 96-well microtiter plates unless otherwise specified. The pooled amplicons $(1 \mu \mathrm{g})$ were fragmented to an average size of 200 bp (between 170 and $250 \mathrm{bp}$ ) using $0.005 \mathrm{U}$ of DNase I for 15 minutes at $37^{\circ} \mathrm{C}$ followed by an inactivation step of 10 minutes at $99^{\circ} \mathrm{C}$. The fragmented DNA was purified in a Qiaquick 96 PCR purification plate (QIAGEN, Valencia, CA, USA) following the manufacturer's instructions. The DNA ends were repaired in a $100 \mu \mathrm{l}$ reaction $(1 \times$ NEB ligase buffer, $1 \mathrm{mg} / \mathrm{ml}$ bovine serum albumin, $200 \mu \mathrm{M}$ dNTP) using $15 \mathrm{U}$ T4 DNA polymerase (NEB Ipswich, MA, USA), $50 \mathrm{U}$ T4 polynucleotide kinase (NEB), and 5 U Klenow DNA polymerase. The reaction was incubated for 30 minutes at $20^{\circ} \mathrm{C}$ and the DNA purified on a Qiaquick 96 PCR purification plate. The 3' end was extended with a single overhanging A using $15 \mathrm{U}$ Klenow exo-, $200 \mu \mathrm{M}$ dATP in $50 \mu \mathrm{l}$ NEB2 reaction buffer and incubated for 30 minutes at $37^{\circ} \mathrm{C}$. The DNA was purified on a Qiaquick 96 PCR purification plate. The eluted DNA was mixed with $10 \mu \mathrm{M}$ of indexed adapters (see sample indexing below and Table S6 in Additional file 1) and ligated for 15 minutes at room temperature with 2,000 U DNA ligase in $50 \mu \mathrm{l}$ ligase buffer (NEB) followed by purification on a Qiaquick 96 PCR purification plate. The DNA was separated from the free adapters by $2 \%$ agarose gel electrophoresis, the smear ranging from 120 to $210 \mathrm{bp}$ was extracted, melted in $3 \mu \mathrm{l}$ QG buffer per milligram of gel for 20 minutes at $50^{\circ}$ in a $800 \mu$ deep well microtiterplate and purified using a Qiaquick 96 PCR purification plate. The adapter ligated fragments were then enriched by PCR using the library enrichment primer 
pairs (Table S6 in Additional file 1) in a $50 \mu \mathrm{l}$ PCR containing $4 \mu \mathrm{l}$ template DNA, Phusion HF buffer (NEB), $200 \mu \mathrm{M} d \mathrm{dTP}, 0.4 \mu \mathrm{M}$ of both Solexa primers, $3 \%$ DMSO, $0.5 \mu$ l Phusion DNA polymerase. The PCR involved denaturing for 5 minutes at $98^{\circ} \mathrm{C}$ followed by 20 cycles of $10 \mathrm{~s}$ at $98^{\circ} \mathrm{C} ; 20 \mathrm{~s}$ at $65^{\circ} \mathrm{C}, 15 \mathrm{~s}$ at $72^{\circ} \mathrm{C}$, and a final elongation of 4 minutes at $72^{\circ} \mathrm{C}$. The DNA library was then purified on a Qiaquick 96 PCR purification plate.

\section{Sample indexing and sequencing}

In order to sequence several samples per lane on the Illumina GA flow cell, we implemented an indexing strategy similar to that described in Craig et al. [53]. We generated 12 pairs of modified DNA adaptors with 4 nucleotide DNA barcodes at the 3' ends; the first and last nucleotides of the DNA barcode were constant while the two middle nucleotides vary (CNNT; Table S6 in Additional file 1). Both strands of the indexed adapter (Integrated DNA Technologies Coralville IA, USA) were mixed at $100 \mu \mathrm{M}$ in TE $\mathrm{pH} 8.0$, denatured for 5 minutes at $95^{\circ} \mathrm{C}$, placed in a heat block at $70^{\circ} \mathrm{C}$, left at room temperature until reaching $25^{\circ} \mathrm{C}$, and then transferred to $4^{\circ} \mathrm{C}$ and left overnight, enabling the two strands to anneal. The annealed strands were then stored at $-20^{\circ} \mathrm{C}$.

The libraries were quantified by Quant-IT technology (Invitrogen) in quadruplicate, diluted to $10 \mathrm{nM}$. From one to seven indexed libraries were combined together into one pool, denatured with $\mathrm{NaOH}$, and then $2.3 \mathrm{pM}$ of each pool was loaded into one lane of an Ilumina GA flow cell and sequenced using Illumina Single-Read Cluster Generation Kit v1 and SBS Kit v1 for 40 cycles, thus providing 36-nucleotide reads after removal of the 4 nucleotides used for DNA barcoding. All the sequencing data are publically available from NCBI short read archive study \#SRP003433.

\section{Image analysis pipeline, read alignment and variant calling}

We used the Illumina Pipeline version 1.0 to analyze the raw images, masking the first four bases of the index (USE_BASE option IIIIY*) for accurate base call calibration. After base calling, quality calibration and read filtering, Python scripts were used to parse out the indexes and create the sequence files for each sample. For paired-end reads, we used the index of the high quality first read to assign the read to a particular sample, regardless of the index from the lower quality second read (matching in $>95 \%$ of the cases).

We used MAQ (version 0.6.8) [26] to align the reads to the reference sequence allowing for three mismatches in the first $24 \mathrm{bp}$ (maq map -n 3). The 289 sample libraries were sequenced across multiple runs of the Illumina GA, 250 samples were sequenced with only paired-end runs, 38 samples were sequenced with at least one paired-end run, and one sample was sequenced in single reads only. For samples sequenced multiple times (with the exception of technical replicate samples of the MultiQC set; see below), the mapped reads were merged to create a single set of mappings for each sample (maq mapmerge). The MAQ variant calling method was used to call variants using default parameters (maq.pl SNPfilter was used to filter out false positives) for each sample. MAQ assigns a most likely genotype for each site and detects potential SNVs in each individual. The set of variants across all 289 samples was combined to create the list of 1,451 raw variants. For each SNV site, we used the MAQ cnsview files to determine the genotype for each sample and the coverage and consensus quality at every position. Genotypes with a quality score below 10 or covered by less than three reads were assigned the NN genotype.

\section{Detection of insertions/deletions}

MAQ outputs all read alignments with indels. We used the filtered indelpe files as the initial set of potential indels. We used the following steps to determine a reliable set of indels from the indelpe files. Step 1, we merged the set of indels reported by MAQ for all 287 samples (2 samples did not have enough paired-end reads). Step 2, we clustered together the indels in multiple samples based on the position of the indels in the reference sequence. This is required since indels located in homopolymer stretches of sequence can have multiple starting locations. Step 3, for each individual, we assigned the genotype for an indel as heterozygote if the proportion of the non-reference reads was between 0.2 and 0.8. Step 4, the genotype was assigned as reference homozygote and alternative homozygote if the proportion was less than 0.2 and more than 0.8 , respectively. Step 5, for each indel detected in the population, we required at least one sample to have three reads with the indel variant and at least eight reads covering the variant site. We imposed stringent cutoffs for rare indels (MAF < 0.01). For such indels, we required coverage of at least 10 with 5 reads containing the indel variant.

\section{Genotyping HapMap SNPs}

The SNPs were genotyped using the Sequenom MassArray genotyping platform. We selected 19 HapMap CEU tag SNPs from the two gene regions (3 in FAAH and 16 in MGGL; Table S7 in Additional file 1). PCR assays and extension primers for these SNPs were designed using the MassARRAY Assay Design software, version 3.1 (Sequenom San Diego CA, USA). SNPs were genotyped using the iPLEX Gold assay, based on multiplex PCR followed by a single base primer extension reaction. The mass of the primer extension products, 
correlating to genotype, were determined using matrix assisted laser desorption/ionization time-of-flight (MALDI-TOF) mass spectrometry. Final genotypes were called using the MassArray Type, version 4.0.

\section{Genotyping obesity SNPs}

The genotypes were determined after PCR and 5' nuclease assay (allelic discrimination with ABI TaqMan specific probes) reaction and read on an ABI 9700 (LIFE Technologies, Carlsbad, CA USA) The PCR primers and probes were chosen according to the supplier (LIFE Technologies, Carlsbad, CA USA). All reagents and software used are licensed to Applied Biosystems. The genotypes were analyzed on an ABI7900 automated sequencer and determined using the SDS2.0(r) allelic discrimination software. No deviations from HardyWeinberg proportions were detected; the genotyping failure rate was $1 \%$.

\section{Sample sets for quality control}

The nine samples were processed as blind replicates, meaning each replicate was treated as an entirely separate sample with independent PCR amplification, library preparation and sequencing as well as analysis. The resulting genotype pairs were compared, assigning the following matching status: 1 , concordant between replicates; 2 , heterozygous versus homozygous alternative; 3 , heterozygous versus homozygous reference with evidence of alternative allele in the raw data (second most likely genotype - near-pass error); 4, heterozygous versus homozygous reference without evidence of alternative allele; 5 , low covered position $(<20 \times)$ in one of the replicates resulting in erroneous genotypes.

\section{Single marker association}

The test for association was performed using PLINK1.06 [54]. The SNPs were filtered for HWE in the controls and genotyping rate $>0.9$. We performed a binary case/ control association using a chi-squared test (-assoc), considering high BMI samples as cases and low BMI samples as controls. The $\max (\mathrm{T})$ permutation $P$-value (-mperm 5000) was obtained after performing 5,000 sample label permutations.

\section{Association with rare variants}

We used the RareCover algorithm described in Bhatia et al. [24]. Briefly, we define $S$ as the set of rare variants (MAF $\leq 0.1$ ) present at a locus $\mathrm{L}_{\mathrm{S}}$, which is a window of size $5 \mathrm{~kb}$. RareCover examines overlapping windows, where each window is shifted one rare variant away from the previous rare variant. We define $C$ as a subset of $\mathrm{S}$ composed of rare variants that contribute to $A_{C}$, the union-variant, a virtual construct that combines the effects of multiple rare variants. The variants in $\mathrm{C}$ together form a locus-variant $\mathrm{L}_{\mathrm{C}}$, and for an individual sample $A_{C}=1$ if at least one of the variants carries the minor allele, and otherwise $A_{C}=0$. By using a chisquare statistic test between high and low BMI samples at the locus $\mathrm{L}_{\mathrm{C}}$, we find the optimal subset of rare variants $C$ for which the association is maximal, thus defining the test-statistic for the locus $\mathrm{L}_{\mathrm{S}}$. The level of significance was obtained by performing $10^{4}$ randomizations of the data set, permuting cases and controls, and re-computing the test-statistic for the selected locus-variant with the permuted samples. A locus $\mathrm{L}_{\mathrm{S}}$ is considered significant if the permuted $P$-value is $<0.01$. To correct for the total number of locus-variant windows tested per gene, another $10^{6}$ permutations of cases and controls were performed and used to evaluate the significance of all locus-variants in the gene [24]. The three locus-variants reported in our study all had a $P$-value $\leq$ 0.05 when corrected for the number of windows tested.

\section{Evolutionarily conserved sequences}

Conserved bases were defined as nucleotides with a conservation score $\geq 0.1758$ ( 5 th percentile in the interval) in the multispecies sequence comparison track at UCSC (28 way placental mammals PhyloP conservation score).

\section{Measurement of endocannabinoid levels in plasma}

Whole blood samples were collected in evacuated glass tubes containing EDTA. Samples were centrifuged to separate plasma from blood cells and plasma was withdrawn and stored in $1-\mathrm{ml}$ aliquots at $-80^{\circ} \mathrm{C}$ prior to plasma lipid extraction. For each sample, $0.5 \mathrm{ml}$ plasma was added to a glass vial containing $2.0 \mathrm{ml}$ chloroform $\left(\mathrm{CHCl}_{3}\right), 1.0 \mathrm{ml}$ methanol $(\mathrm{MeOH})$ and $0.5 \mathrm{ml}(1 \% \mathrm{v} / \mathrm{v})$ formic acid. To this mixture were added aliquots of 10 pmol D5-2-arachidonlyglycerol (2-AG) and 5 pmol D8arachidonlyethanolamine (AEA). Vial contents were vortex mixed for $30 \mathrm{~s}$ and centrifuged at $10^{\circ} \mathrm{C}(1400 \times \mathrm{g}$ for 10 minutes). The organic layer was carefully removed avoiding the aqueous layer and dried under a stream of nitrogen $\left(\mathrm{N}_{2}\right)$ gas. The lipid layer was then re-solubilized in $100 \mu \mathrm{l}$ of $2: 1 \mathrm{CHCl}_{3}: \mathrm{CH}_{3} \mathrm{OH}$.

Quantitative analysis of EC metabolites using the deuterated standards for AEA and 2-AG together with calculation of the other EC metabolites was based on a ratio to the deuterated standards and was performed on an Agilent 6410 liquid chromatography triple-quadrupole mass spectrometer using positive ion analysis mode. For each sample, $20 \mu \mathrm{l}$ of re-solubilized plasma lipids were injected into the TQMS and EC metabolites were measured by multiple reaction monitoring using the following transitions: $348>62$ (AEA), fragmentation energy $=8$; and $379>287$ (2-AG), fragmentation energy $=11$. Chromatography was performed using the following solvents: A, 95:5:0.1 $\mathrm{H}_{2} \mathrm{O}$ :methanol:formic acid; and 
B, 60:35:5:0.1 isopropanol:methanol: $\mathrm{H}_{2} \mathrm{O}$ :formic acid. Lipids were injected into a 5 micron particle size C18 column $(50 \times 4.6 \mathrm{~mm})$ from Phenomenex (Torrance, CA, USA) and eluted with a 10-minute solvent B gradient from $60 \%$ to $100 \%$. Values for each EC metabolite were subsequently calculated using ratios to the deuterated internal standards to calculate absolute concentrations, expressed as picomoles ( $\mathrm{pmol}$ ) of EC metabolite per milliliter of plasma similar to current methods [55].

\section{Additional material}

\section{Additional file 1: Supplementary tables.}

Additional file 2: Supplementary Figure S3. Flowchart illustrating the filtering steps for the variant calling.

Additional file 3: Supplementary Figure S1. Distribution of the minor allele frequencies in the sequenced population for SNVs present in dbSNP (light grey) or novel SNVs (dark grey) in the FAAH and MGLL sequenced intervals.

Additional file 4: Supplementary Figure S2. Average AEA plasma levels $(\mathrm{pmol} / \mathrm{ml})$ in 48 non-carriers controls, 80 non-carrier cases and 14 case carriers of the most significant $F A A H$ variant-locus allele associated with high BMI. Error bars represent the standard deviation from the mean.

\section{Abbreviations}

2-AG: 2-arachidonoylglycerol; AEA: anandamide; BMI: body mass index; bp: base pair; EC: endocannabinoid; FAAH: fatty-acid amide hydrolase; GWAS: genome wide association study; HWE: Hardy-Weinberg equilibrium; indel: insertion-deletion; LD: linkage disequilibrium; LR-PCR: long range PCR; MAF: minor allele frequency; MGLL: monoglyceride lipase; SNP: single nucleotide polymorphism; SNV: single nucleotide variant; TQMS: triple-quadrupole mass spectrometry.

\section{Acknowledgements}

We thank Karrie Trevarthen, Marian Shaw, Terri Gelbart, Stéphane Soubigou, Gaelle Muzard and Sandrine Roche for excellent technical assistance and Kari Ohlsen for the sample selection. We are grateful to Gabriel Simon and Benjamin Cravatt for sharing their data with us. This work was partly supported by NSF grant IIS-08109 to VB, NIH CTSA grant NIH 1U54RR02520401 to EJT and $\mathrm{NIH-NCl}$ grant CA152613-01 to KAF.

\section{Author details}

${ }^{1}$ Moores UCSD Cancer Center, University of California San Diego, 9500 Gilman Drive, La Jolla, CA 92093, USA. ²Department of Pediatrics and Rady's Childrens Hospital, University of California San Diego, 9500 Gilman Drive, La Jolla, CA 92093, USA. ${ }^{3}$ Scripps Genomic Medicine, Scripps Translational Science Institute, 3344 North Torrey Pines Court Suite 300, La Jolla, CA 92037, USA. ${ }^{4}$ Department of Computer Sciences, University of California San Diego, 9500 Gilman Drive, La Jolla, CA 92093, USA. ${ }^{5}$ Department of Molecular and Experimental Medicine, The Scripps Research Institute, 10550 North Torrey Pines Road, La Jolla, CA 92037, USA. 'Sanofi-Aventis Evry Genetics Center, 2 rue Gaston Cremieux, 91057 Evry, France. ${ }^{7}$ Institute for Genomic Medicine, University of California San Diego, 9500 Gilman Drive, La Jolla, CA 92093, USA.

\section{Authors' contributions}

$\mathrm{OH}$ and VB performed the sequencing and statistical analysis. GB and VB performed the rare variant analysis. MS and JS performed the mass spectrometry experiments. $\mathrm{OH}, \mathrm{XW}$ and $\mathrm{MN}$ designed and performed nextgeneration sequencing experiments; SM designed and performed the MassARRAY genotyping. JFD, CD, ET provided the samples and performed genotyping experiments. KAF, EJT, JFD, SM and $\mathrm{OH}$ designed the study. KAF and $\mathrm{OH}$ wrote the manuscript.
Received: 28 June 2010 Revised: 28 August 2010

Accepted: 30 November 2010 Published: 30 November 2010

\section{References}

1. Reich DE, Lander ES: On the allelic spectrum of human disease. Trends Genet 2001, 17:502-510.

2. Frazer KA, Ballinger DG, Cox DR, Hinds DA, Stuve LL, Gibbs RA, Belmont JW, Boudreau A, Hardenbol P, Leal SM, Pasternak S, Wheeler DA, Willis TD, Yu F, Yang H, Zeng C, Gao Y, Hu H, Hu W, Li C, Lin W, Liu S, Pan H, Tang X, Wang J, Wang W, Yu J, Zhang B, Zhang Q, Zhao H, et al: A second generation human haplotype map of over 3.1 million SNPs. Nature 2007, 449:851-861.

3. Fan JB, Chee MS, Gunderson KL: Highly parallel genomic assays. Nat Rev Genet 2006, 7:632-644.

4. Manolio TA, Collins FS, Cox NJ, Goldstein DB, Hindorff LA, Hunter DJ, McCarthy MI, Ramos EM, Cardon LR, Chakravarti A, Cho JH, Guttmacher AE, Kong A, Kruglyak L, Mardis E, Rotimi CN, Slatkin M, Valle D, Whittemore AS, Boehnke M, Clark AG, Eichler EE, Gibson G, Haines JL, Mackay TF, McCarroll SA, Visscher PM: Finding the missing heritability of complex diseases. Nature 2009, 461:747-753.

5. Walley AJ, Asher JE, Froguel P: The genetic contribution to non-syndromic human obesity. Nat Rev Genet 2009, 10:431-442

6. Frayling TM, Timpson NJ, Weedon MN, Zeggini E, Freathy RM, Lindgren CM, Perry JR, Elliott KS, Lango H, Rayner NW, Shields B, Harries LW, Barrett JC, Ellard S, Groves CJ, Knight B, Patch AM, Ness AR, Ebrahim S, Lawlor DA, Ring SM, Ben-Shlomo Y, Jarvelin MR, Sovio U, Bennett AJ, Melzer D, Ferrucci L, Loos RJ, Barroso I, Wareham NJ, et al: A common variant in the FTO gene is associated with body mass index and predisposes to childhood and adult obesity. Science 2007, 316:889-894.

7. Loos RJ, Lindgren CM, Li S, Wheeler E, Zhao JH, Prokopenko I, Inouye M, Freathy RM, Attwood AP, Beckmann JS, Berndt SI, Jacobs KB, Chanock SJ, Hayes RB, Bergmann S, Bennett AJ, Bingham SA, Bochud M, Brown M, Cauchi S, Connell JM, Cooper C, Smith GD, Day I, Dina C, De S, Dermitzakis ET, Doney AS, Elliott KS, Elliott P, et al: Common variants near MC4R are associated with fat mass, weight and risk of obesity. Nat Genet 2008, 40:768-775.

8. Liu YJ, Liu XG, Wang L, Dina C, Yan H, Liu JF, Levy S, Papasian CJ, Drees BM, Hamilton JJ, Meyre D, Delplanque J, Pei YF, Zhang L, Recker RR, Froguel P, Deng HW: Genome-wide association scans identified CTNNBL1 as a novel gene for obesity. Hum Mol Genet 2008, 17:1803-1813.

9. Rodriguez de Fonseca F, Del Arco I, Bermudez-Silva FJ, Bilbao A, Cippitelli A, Navarro M: The endocannabinoid system: physiology and pharmacology. Alcohol Alcohol 2005, 40:2-14.

10. Walker JM, Krey JF, Chu CJ, Huang SM: Endocannabinoids and related fatty acid derivatives in pain modulation. Chem Phys Lipids 2002, 121:159-172.

11. Benzinou M, Chevre JC, Ward KJ, Lecoeur C, Dina C, Lobbens S, Durand E, Delplanque J, Horber FF, Heude B, Balkau B, Borch-Johnsen K, Jorgensen T, Hansen T, Pedersen O, Meyre D, Froguel P: Endocannabinoid receptor 1 gene variations increase risk for obesity and modulate body mass index in European populations. Hum Mol Genet 2008, 17:1916-1921.

12. Kirkham TC: Endocannabinoids in the regulation of appetite and body weight. Behav Pharmacol 2005, 16:297-313.

13. Kunos G, Osei-Hyiaman D, Liu J, Godlewski G, Batkai S: Endocannabinoids and the control of energy homeostasis. J Biol Chem 2008, 283:33021-33025.

14. Osei-Hyiaman D, DePetrillo M, Pacher P, Liu J, Radaeva S, Batkai S, HarveyWhite J, Mackie K, Offertaler L, Wang L, Kunos G: Endocannabinoid activation at hepatic $C B 1$ receptors stimulates fatty acid synthesis and contributes to diet-induced obesity. J Clin Invest 2005, 115:1298-1305.

15. Starowicz KM, Cristino L, Matias I, Capasso R, Racioppi A, Izzo AA, Di Marzo V: Endocannabinoid dysregulation in the pancreas and adipose tissue of mice fed with a high-fat diet. Obesity (Silver Spring) 2008, 16:553-565.

16. Engeli S, Bohnke J, Feldpausch M, Gorzelniak K, Janke J, Batkai S, Pacher P, Harvey-White J, Luft FC, Sharma AM, Jordan J: Activation of the peripheral endocannabinoid system in human obesity. Diabetes 2005, 54:2838-2843.

17. Cote M, Matias I, Lemieux I, Petrosino S, Almeras N, Despres JP, Di Marzo V: Circulating endocannabinoid levels, abdominal adiposity and related cardiometabolic risk factors in obese men. Int J Obes (Lond) 2007, 31:692-699. 
18. Sipe JC, Waalen J, Gerber A, Beutler E: Overweight and obesity associated with a missense polymorphism in fatty acid amide hydrolase (FAAH). Int J Obes (Lond) 2005, 29:755-759.

19. Chiang KP, Gerber AL, Sipe JC, Cravatt BF: Reduced cellular expression and activity of the P129T mutant of human fatty acid amide hydrolase: evidence for a link between defects in the endocannabinoid system and problem drug use. Hum Mol Genet 2004, 13:2113-2119.

20. Cohen JC, Pertsemlidis A, Fahmi S, Esmail S, Vega GL, Grundy SM, Hobbs HH: Multiple rare variants in NPC1L1 associated with reduced sterol absorption and plasma low-density lipoprotein levels. Proc Nat Acad Sci USA 2006, 103:1810-1815.

21. Wood LD, Parsons DW, Jones S, Lin J, Sjoblom T, Leary RJ, Shen D, Boca SM, Barber T, Ptak J, Silliman N, Szabo S, Dezso Z, Ustyanksky V, Nikolskaya T, Nikolsky Y, Karchin R, Wilson PA, Kaminker JS, Zhang Z, Croshaw R, Willis J, Dawson D, Shipitsin M, Willson JK, Sukumar S, Polyak K, Park BH, Pethiyagoda CL, Pant PV, et al: The genomic landscapes of human breast and colorectal cancers. Science 2007, 318:1108-1113.

22. Ng SB, Turner EH, Robertson PD, Flygare SD, Bigham AW, Lee C, Shaffer T, Wong M, Bhattacharjee A, Eichler EE, Bamshad M, Nickerson DA, Shendure J: Targeted capture and massively parallel sequencing of 12 human exomes. Nature 2009, 461:272-276.

23. Yeager M, Xiao N, Hayes RB, Bouffard P, Desany B, Burdett L, Orr N, Matthews C, Qi L, Crenshaw A, Markovic Z, Fredrikson KM, Jacobs KB, Amundadottir L, Jarvie TP, Hunter DJ, Hoover R, Thomas G, Harkins TT, Chanock SJ: Comprehensive resequence analysis of a $136 \mathrm{~kb}$ region of human chromosome $8 \mathrm{q} 24$ associated with prostate and colon cancers. Hum Genet 2008, 124:161-170.

24. Bhatia G, Bansal V, Harismendy O, Schork NJ, Topol EJ, Frazer K, Bafna V: A covering method for detecting genetic associations between rare variants and common phenotypes. PLoS Comput Biol 2010, 6:e1000954

25. Harismendy O, Ng PC, Strausberg RL, Wang X, Stockwell TB, Beeson KY, Schork NJ, Murray SS, Topol EJ, Levy S, Frazer KA: Evaluation of next generation sequencing platforms for population targeted sequencing studies. Genome Biol 2009, 10:R32.

26. Li H, Ruan J, Durbin R: Mapping short DNA sequencing reads and calling variants using mapping quality scores. Genome Res 2008, 18:1851-1858.

27. Huebner C, Petermann I, Browning BL, Shelling AN, Ferguson LR: Triallelic single nucleotide polymorphisms and genotyping error in genetic epidemiology studies: MDR1 (ABCB1) G2677/T/A as an example. Cancer Epidemiol Biomarkers Prev 2007, 16:1185-1192.

28. Ng PC, Henikoff S: SIFT: Predicting amino acid changes that affect protein function. Nucleic Acids Res 2003, 31:3812-3814.

29. Bentley DR, Balasubramanian S, Swerdlow HP, Smith GP, Milton J, Brown CG, Hall KP, Evers DJ, Barnes CL, Bignell HR, Boutell JM, Bryant J, Carter RJ, Keira Cheetham R, Cox AJ, Ellis DJ, Flatbush MR, Gormley NA, Humphray SJ, Irving LJ, Karbelashvili MS, Kirk SM, Li H, Liu X, Maisinger KS, Murray LJ, Obradovic B, Ost T, Parkinson ML, Pratt MR, et al: Accurate whole human genome sequencing using reversible terminator chemistry. Nature 2008, 456:53-59.

30. Bansal V, Harismendy O, Tewhey R, Murray SS, Schork NJ, Topol EJ, Frazer KA: Accurate detection and genotyping of SNPs utilizing population sequencing data. Genome Res 2010, 20:537-545.

31. Levy $S$, Sutton $G, N g P C$, Feuk $L$, Halpern AL, Walenz BP, Axelrod N, Huang J, Kirkness EF, Denisov G, Lin Y, MacDonald JR, Pang AW, Shago M, Stockwell TB, Tsiamouri A, Bafna V, Bansal V, Kravitz SA, Busam DA, Beeson KY, McIntosh TC, Remington KA, Abril JF, Gill J, Borman J, Rogers YH, Frazier ME, Scherer SW, Strausberg RL, Venter JC: The diploid genome sequence of an individual human. PLOS BiOl 2007, 5:e254.

32. Hinney A, Nguyen $T$, Scherag A, Friedel $S$, Bronner G, Muller TD, Grallert $H$, Illig T, Wichmann HE, Rief W, Schafer H, Hebebrand J: Genome wide association (GWA) study for early onset extreme obesity supports the role of fat mass and obesity associated gene (FTO) variants. PLOS One 2007, 2:e1361.

33. Dina C, Meyre D, Gallina S, Durand E, Korner A, Jacobson P, Carlsson LM, Kiess W, Vatin V, Lecoeur C, Delplanque J, Vaillant E, Pattou F, Ruiz J, Weill J, Levy-Marchal C, Horber F, Potoczna N, Hercberg S, Le Stunff C, Bougneres $\mathrm{P}$, Kovacs $\mathrm{P}$, Marre M, Balkau B, Cauchi S, Chevre JC, Froguel P. Variation in FTO contributes to childhood obesity and severe adult obesity. Nat Genet 2007, 39:724-726.

34. Grant SF, Li M, Bradfield JP, Kim CE, Annaiah K, Santa E, Glessner JT, Casalunovo T, Frackelton EC, Otieno FG, Shaner JL, Smith RM, Imielinski M,
Eckert AW, Chiavacci RM, Berkowitz RI, Hakonarson H: Association analysis of the FTO gene with obesity in children of Caucasian and African ancestry reveals a common tagging SNP. PLOS One 2008, 3:e1746.

35. Scuteri A, Sanna S, Chen WM, Uda M, Albai G, Strait J, Najjar S, Nagaraja R, Orru M, Usala G, Dei M, Lai S, Maschio A, Busonero F, Mulas A, Ehret GB, Fink AA, Weder AB, Cooper RS, Galan P, Chakravarti A, Schlessinger D, Cao A, Lakatta E, Abecasis GR: Genome-wide association scan shows genetic variants in the FTO gene are associated with obesity-related traits. PLoS Genet 2007, 3:e115.

36. Chambers JC, Elliott P, Zabaneh D, Zhang W, Li Y, Froguel P, Balding D, Scott J, Kooner JS: Common genetic variation near MC4R is associated with waist circumference and insulin resistance. Nat Genet 2008, 40:716-718.

37. Zobel DP, Andreasen CH, Grarup N, Eiberg H, Sorensen Tl, Sandbaek A, Lauritzen T, Borch-Johnsen K, Jorgensen T, Pedersen O, Hansen T: Variants near MC4R are associated with obesity and influence obesity-related quantitative traits in a population of middle-aged people: studies of 14,940 Danes. Diabetes 2009, 58:757-764.

38. Peeters A, Beckers S, Mertens I, Van Hul W, Van Gaal L: The G1422A variant of the cannabinoid receptor gene (CNR1) is associated with abdominal adiposity in obese men. Endocrine 2007, 31:138-141.

39. Russo P, Strazzullo P, Cappuccio FP, Tregouet DA, Lauria F, Loguercio M, Barba G, Versiero M, Siani A: Genetic variations at the endocannabinoid type 1 receptor gene (CNR1) are associated with obesity phenotypes in men. J Clin Endocrinol Metab 2007, 92:2382-2386.

40. Hall DH, Rahman T, Avery PJ, Keavney B: INSIG-2 promoter polymorphism and obesity related phenotypes: association study in 1428 members of 248 families. BMC Med Genet 2006, 7:83.

41. Heid IM, Huth C, Loos RJ, Kronenberg F, Adamkova V, Anand SS, Ardlie K, Biebermann H, Bjerregaard P, Boeing H, Bouchard C, Ciullo M, Cooper JA, Corella D, Dina C, Engert JC, Fisher E, Frances F, Froguel P, Hebebrand J, Hegele RA, Hinney A, Hoehe MR, Hu FB, Hubacek JA, Humphries SE, Hunt SC, Illig T, Jarvelin MR, Kaakinen M, et al: Meta-analysis of the INSIG2 association with obesity including 74,345 individuals: does heterogeneity of estimates relate to study design? PLOS Genet 2009, 5 e1000694.

42. Cohen JC, Kiss RS, Pertsemlidis A, Marcel YL, McPherson R, Hobbs HH: Multiple rare alleles contribute to low plasma levels of HDL cholesterol. Science 2004, 305:869-872.

43. Fearnhead NS, Wilding JL, Winney B, Tonks S, Bartlett S, Bicknell DC, Tomlinson IP, Mortensen NJ, Bodmer WF: Multiple rare variants in different genes account for multifactorial inherited susceptibility to colorectal adenomas. Proc Natl Acad Sci USA 2004, 101:15992-15997.

44. Nejentsev S, Walker N, Riches D, Egholm M, Todd JA: Rare variants of IFIH1, a gene implicated in antiviral responses, protect against type 1 diabetes. Science 2009, 324:387-389.

45. Heintzman ND, Hon GC, Hawkins RD, Kheradpour P, Stark A, Harp LF, Ye Z, Lee LK, Stuart RK, Ching CW, Ching KA, Antosiewicz-Bourget JE, Liu H, Zhang X, Green RD, Lobanenkov W, Stewart R, Thomson JA, Crawford GE, Kellis $M$, Ren B: Histone modifications at human enhancers reflect global cell-type-specific gene expression. Nature 2009, 459:108-112.

46. The ENCODE (ENCyclopedia Of DNA Elements) Project. Science 2004, 306:636-640

47. Johansen $C T$, Wang J, Lanktree MB, Cao H, McIntyre AD, Ban MR, Martins RA, Kennedy BA, Hassell RG, Visser ME, Schwartz SM, Voight BF, Elosua R, Salomaa V, O'Donnell CJ, Dallinga-Thie GM, Anand SS, Yusuf S, Huff MW, Kathiresan S, Hegele RA: Excess of rare variants in genes identified by genome-wide association study of hypertriglyceridemia. Nat Genet 42:684-687.

48. Tuupanen $\mathrm{S}$, Turunen M, Lehtonen R, Hallikas O, Vanharanta S, Kivioja T, Björklund M, Wei G, Yan J, Niittymäki I, Mecklin JP, Järvinen H, Ristimäki A, Di-Bernardo M, East P, Carvajal-Carmona L, Houlston RS, Tomlinson I, Palin K, Ukkonen E, Karhu A, Taipale J, Aaltonen LA: The common colorectal cancer predisposition SNP rs6983267 at chromsome 8q24 confers potential to enhanced Wnt signaling. Nat Genet 2009, 41:885-890.

49. Pomerantz MM, Ahmadiyeh N, Jia L, Herman P, Verzi MP, Doddapaneni H, Beckwith CA, Chan JA, Hills A, Davis M, Yao K, Kehoe SM, Lenz HJ, Haiman CA, Yan C, Henderson BE, Frenkel B, Barretina J, Bass A, Tabernero J, Baselga J, Regan MM, Manak JR, Shivdasani R, Coetzee GA, Freedman ML: The 8q24 cancer risk variant rs6983267 shows long-range interaction with MYC in colorectal cancer. Nat Genet 2009, 41:882-884. 
50. CRESCENDO clinical trial. [http://clinicaltrials.gov/ct/show/NCT00263042].

51. Li JZ, Absher DM, Tang H, Southwick AM, Casto AM, Ramachandran S, Cann HM, Barsh GS, Feldman M, Cavalli-Sforza LL, Myers RM: Worldwide human relationships inferred from genome-wide patterns of variation. Science 2008, 319:1100-1104.

52. Patterson N, Price AL, Reich D: Population structure and eigenanalysis. PLoS Genet 2006, 2:e190

53. Craig DW, Pearson JV, Szelinger S, Sekar A, Redman M, Corneveaux JJ, Pawlowski TL, Laub T, Nunn G, Stephan DA, Homer N, Huentelman MJ: Identification of genetic variants using bar-coded multiplexed sequencing. Nat Methods 2008, 5:887-893.

54. Purcell $S$, Neale B, Todd-Brown K, Thomas L, Ferreira MA, Bender D, Maller J, Sklar P, de Bakker PI, Daly MJ, Sham PC: PLINK: a tool set for wholegenome association and population-based linkage analyses. Am J Hum Genet 2007, 81:559-575.

55. Palandra J, Prusakiewicz J, Ozer JS, Zhang Y, Heath TG: Endogenous ethanolamide analysis in human plasma using HPLC tandem MS with electrospray ionization. J Chromatogr B Analyt Technol Biomed Life Sci 2009, 877:2052-2060.

56. Myers S, Bottolo L, Freeman C, McVean G, Donnelly P: A fine-scale map of recombination rates and hotspots across the human genome. Science 2005, 310:321-324.

doi:10.1186/gb-2010-11-11-r118

Cite this article as: Harismendy et al.: Population sequencing of two endocannabinoid metabolic genes identifies rare and common regulatory variants associated with extreme obesity and metabolite level. Genome Biology 2010 11:R118.

\section{Submit your next manuscript to BioMed Central} and take full advantage of:

- Convenient online submission

- Thorough peer review

- No space constraints or color figure charges

- Immediate publication on acceptance

- Inclusion in PubMed, CAS, Scopus and Google Scholar

- Research which is freely available for redistribution

Submit your manuscript at www.biomedcentral.com/submit
Ciomed Central 